ARTÍCULO

\title{
DOS DÉCADAS DE TESIS DE FARMACIA EN MÉXICO (1897-1919)
}

TWO DECADES OF PHARMACY DISSERTATIONS IN MEXICO (1897-1919)

\author{
Mariana ORTIZ-REYNOSO \\ Universidad Autónoma del Estado de México \\ mortizr@uaemex.mx \\ Liliana Schifter ACEves \\ Universidad Autónoma Metropolitana-Xochimilco \\ liliana_schifter@hotmail.com
}

\section{Irlanda Geraldine Muciño MuriLlo}

Farmacéutica Hispanoamericana

geraldine_m1991@hotmail.com

\section{Resumen}

El presente trabajo analiza por primera vez las 39 tesis de la carrera de Farmacia elaboradas por los alumnos de la Escuela Nacional de Medicina (ENM) entre 1897 y 1919. Los trabajos abarcan principalmente temas relativos al análisis químico de diversos tipos de sustratos, estudios relacionados con plantas medicinales, aplicaciones bacteriológicas a procesos farmacéuticos, particularidades de algunas formas farmacéuticas y en menor medida aspectos de legislación, historia y ejercicio farmacéuticos. Las tesis de farmacia analizadas en este trabajo son fuentes primarias de información valiosa ya que permiten conocer el nivel de desarrollo de la disciplina y establecer la relación entre el perfil profesional y el quehacer de los farmacéuticos mexicanos de la ENM a finales del siglo XIX y principios del xx. El análisis de estos textos ayudará a comprender los elementos emergentes que dieron lugar a la transformación de un profesional experto en farmacia galénica a uno orientado hacia el análisis químico de medicamentos y otros productos.

Palabras clave: farmacéutico, Escuela Nacional de Medicina, tesis de farmacia, historia de la farmacia mexicana siglos XIX y Xx.

\section{Abstract}

This paper analyzes for the first time the 39 Pharmacy career theses written by graduates of the National School of Medicine (NSM) between 1897 and 1919. The reviewed documents include topics mainly related to the chemical analysis of various types of substrata, medicinal plants, bacteriological applications to pharmaceutical processes, particularities of some pharmaceutical forms and topics such as pharmaceutical legislation, history and practice. The examined texts are valuable primary sources for identifying the development of this field of study concerning the professional profile and work performed by Mexican pharmacists of the NSM in the late 19th and early 20th centuries. The analysis of these texts helps us to understand the emerging practices and knowledge that led to the transformation of 
galenic pharmacy experts into chemists oriented to the analysis of medicines and other products.

Keywords: Pharmacist, National School of Medicine, pharmaceutical theses, history of pharmacy 19th and 20th centuries.

Información del artículo

Recibido: 27 de septiembre de 2019.

Aceptado: 27 de enero de 2020.

DOI: $10.22201 /$ iih.24485004e.2019.58.70956

\section{INTRODUCCIÓN}

En 2002 se publicó un libro que analiza con detalle las 97 tesis de Farmacia que fueron escritas en el periodo de 1867 a 1896 y que permitió valorar las aportaciones de la Escuela Nacional de Medicina (ENM) a las publicaciones científicas del gremio farmacéutico, especialmente a la farmacopea mexicana. Este trabajo también coadyuvó a establecer la conformación de las redes científico-académicas del área química y farmacéutica, principalmente en el Instituto Médico Nacional (IMN) y a establecer el grado de desarrollo de otros espacios de investigación y práctica médica de la ciencia mexicana. ${ }^{1}$

El presente trabajo es una continuación de ese estudio y su objetivo es determinar si los temas de investigación de las tesis de Farmacia analizadas guardan relación con los cambios en la orientación del quehacer farmacéutico ocurridos durante el periodo comprendido entre 1897 y 1919. Es decir, si además de los temas concernientes al análisis de los productos naturales predominantes durante todo el siglo xix, se abordan otros que pongan de manifiesto el acercamiento de los farmacéuticos a los campos emergentes en el ámbito del análisis químico, como el análisis de fluidos biológicos, la toxicología y la química de alimentos. Asimismo, se pretende determinar si se observa un cambio en el perfil profesional de los farmacéuticos en relación con el gradual pero definitivo abandono de las preparaciones magistrales fabricadas a pequeña escala en las boticas en favor de los procesos

${ }^{1}$ Mariana Ortiz-Reynoso, Las tesis de farmacia del siglo XIX mexicano, México, Universidad Autónoma Metropolitana-Unidad Xochimilco/Sociedad Química de México/Colegio Nacional de Químicos Farmacéuticos Biólogos, 2002. Otros estudios acerca de este tema incluyen el libro, que es una referencia importante para estudiar estos textos fuera de la capital mexicana, Las tesis académicas de las Ciencias Químico Biológicas en Sinaloa, 1875-1974, edición de Leonel Rodríguez-Benítez, México, Universidad Autónoma de Sinaloa, 2017. 
industriales de la química farmacéutica en nuestro país. Emprender el análisis de estos textos implica considerar el contexto social, científico y político de la época para ampliar nuestra comprensión sobre las causas que llevaron a la transformación del perfil profesional de los farmacéuticos en la segunda década del siglo xx. ${ }^{2}$

El método utilizado se corresponde con el de una investigación histórica, es decir, incluye la búsqueda, identificación, selección, análisis e interpretación de fuentes primarias y secundarias. De igual manera abarca las técnicas de investigación bibliográfica, hemerográfica y documental. Los materiales analizados incluyen principalmente las tesis de Farmacia que están bajo resguardo en el Archivo Histórico de la Facultad de Medicina de la Universidad Nacional Autónoma de México, ubicado en el Centro Histórico de la Ciudad de México, así como diversos textos, revistas, leyes y decretos expedidos durante el periodo de estudio.

La delimitación temporal tiene como punto de partida el año de 1897, que se corresponde con el primer año en que las tesis no han sido abordadas por la historiografía, mientras que el cierre del estudio se establece en 1919, año en el que la carrera de Farmacia se incorporó a la Facultad de Química de la Universidad Nacional de México, separándose de forma definitiva de la Medicina. La carrera de Farmacia, que se cursaba desde 1833 en la Escuela Nacional de Medicina, no era bien vista por los médicos de esta institución ya que la consideraban inferior a la Medicina. Con el crecimiento de las disputas entre médicos y farmacéuticos en los primeros años del siglo $\mathrm{xx}$, estos últimos comenzaron a buscar otros lugares para continuar sus estudios profesionales. Estos esfuerzos culminaron con la incorporación de la carrera de Farmacia a la Facultad de Ciencias Químicas, donde a partir de 1921 comenzaría a impartirse de la carrera de químico farmacéutico.

El análisis de las tesis de Farmacia objeto de este estudio se hizo con el fin de delimitar los ejes temáticos relevantes para la ciencia nacional, ubicar espacios de trabajo, examinar las colaboraciones entre investigadores, reconocer a los autores citados y en la medida de lo posible, identificar los instrumentos y técnicas utilizados por los alumnos de Farmacia de la ENM en la ciudad de México durante las primeras décadas del siglo xx.

\footnotetext{
${ }^{2}$ Sandra Martínez, Patricia Aceves y Alba Morales-Cosme, "Una nueva identidad para los farmacéuticos: la Sociedad Farmacéutica Mexicana en el cambio de siglo (1890-1919)”, Dynamis, v. 27, 2007.
} 


\section{LA FARMACIA MEXICANA EN LA SEGUNDA MITAD DEL SIGLO XIX}

El contexto histórico en que se desarrollaron estas tesis comprende dos periodos del país sumamente distintos entre sí. El primero corresponde al llamado segundo Porfiriato (1890 a 1908), en el que se manifestaron un acentuado centralismo y un modelo económico que favoreció el desarrollo de algunos sectores industriales como la minería de exportación y las comunicaciones ferroviarias. En contraparte, durante la Revolución Mexicana (1910-1920) estalló una lucha armada que esencialmente intentó recuperar las tierras, los recursos del subsuelo, el petróleo y los ferrocarriles de manos extranjeras y aminorar la abismal diferencia entre las clases sociales del país. Hasta el momento, no hemos encontrado tesis de Farmacia elaboradas durante este segundo periodo. A diferencia de otras actividades que no se interrumpieron, como la solicitud de patentes industriales, ${ }^{3}$ al parecer la producción de tesis académicas se detuvo completamente o por lo menos su registro. ${ }^{4}$

En el plano económico, a partir de 1894 se alcanzó un superávit. Para la última década del siglo XIX los sistemas productivos se habían transformado; en la ciudad de México y en algunos estados del país como Nuevo León, Jalisco, Puebla y Veracruz se había desarrollado la industria ligera con fábricas modernas que utilizaban energía hidráulica, eléctrica o de vapor. Las industrias de bienes de consumo estaban dedicadas a la producción de cigarros, zapatos, cerámica, papel, textiles, vidrio y cerveza, ${ }^{5}$ pero no a los insumos farmacéuticos. Salvo las excepciones de la Farmacia Bustillos, establecida en 1854 y la droguería de los italianos Grisi fundada en 1912, que luego se convertirían en laboratorios productores de medicamentos, la industria farmacéutica nacional aún no despegaba. Durante la segunda década del siglo xx, se instalaron la Compañía Medicinal La Campana (1917) y la empresa Carlos Stein \& Compañía (1919), ambas con capital extranjero. ${ }^{6}$

${ }^{3}$ Mariana Ortiz-Reynoso, Liliana Schifter-Aceves, Valeria Zepeda-Trejo, "Pharmaceutical Patents in Mexico at the Beginning of the 20th Century", en Historia da Ciencia na PUC-SP: uma viagem de 20 anos, San Pablo, Editora da Pontificia Universidade Católica de Sao Paulo (2019, en prensa).

${ }^{4}$ Alfonso Teja Zabre, Guía de la historia de México, México, Secretaría de Educación Pública, 1944.

${ }^{5}$ Elisa Speckman Guerra, "El Porfiriato”, en Nueva historia mínima de México, México, El Colegio de México, 2004, p. 192-224.

${ }^{6}$ Rogelio Godínez, "Los primeros medicamentos químicos en México (1917-1940)”, Boletín de la Sociedad Química de México, v. 6, n. 1, 2012, p. 8-14. 
En ambos periodos, la configuración de la administración pública obedeció a las circunstancias económico-políticas y culturales del país, así como a los avances científicos. En 1890 se creó la Secretaría de Comunicaciones y Obras Públicas, conservando otras creadas tras la independencia: secretarías del Interior, de Relaciones Exteriores, de Justicia y Negocios Eclesiásticos, de Hacienda Pública, de Guerra y Marina y de Fomento Industrial.

Esta última fue establecida en 1835 y es materia de estudio para la historia de la farmacia ya que estuvo encargada de otorgar las patentes industriales (entre ellas las de tipo farmacéutico). Asimismo, cuando el IMN comenzó sus trabajos quedó adscrito a esta dependencia, y fue así hasta 1908. Como veremos más adelante, este último hecho muestra el esfuerzo motivado desde el gobierno para apoyar la investigación científica aplicada al aprovechamiento de los recursos naturales en beneficio de la salud. ${ }^{7}$

Por otra parte es importante mencionar que durante la segunda mitad del siglo Xıx, la popularización de las técnicas de análisis químico y los nuevos descubrimientos relativos a la síntesis orgánica impulsó el surgimiento de los laboratorios farmacéuticos de escala industrial en Estados Unidos y Europa. ${ }^{8}$ Con el aislamiento de la morfina a partir del opio a principios de siglo se inició una carrera por identificar y aislar los principios activos de las plantas. Los nuevos medicamentos químicos que surgieron como consecuencia de estos esfuerzos, pronto estuvieron disponibles al público en general en numerosas boticas, farmacias, droguerías y otros establecimientos afines. ${ }^{9}$ En estas latitudes, el efecto secundario de la Revolución Industrial promovió la introducción de maquinaria pesada en procesos de fabricación y el desarrollo de formas farmacéuticas convenientes para su producción en masa tales como tabletas, píldoras, cápsulas y

7 Tras el movimiento revolucionario se crearon las secretarías de Gobernación, de Relaciones Exteriores, de Hacienda y Crédito Público, de Guerra y Marina, de Comunicaciones y Obras Públicas y de Industria, Comercio y Trabajo, y se establecieron los departamentos: Judicial, Universitario y de Bellas Artes y de Salubridad Pública. Lucio Mendieta y Núñez, "La administración pública”, en México. 50 años de Revolución. III. Política, México, Fondo de Cultura Económica, 1961.

${ }^{8}$ Raúl Rodríguez-Nozal y Antonio González-Bueno, Entre el arte y la técnica. Los orígenes de la fabricación industrial del medicamento, Madrid, Consejo Superior de Investigaciones Científicas, 2005, p. 82; Rogelio Godínez y Patricia Aceves, Proyectos, realidades y utopías. La transformación de la Farmacia en México, 1919-1940, México, Universidad Autónoma Metropolitana-Unidad Xochimilco, División de Ciencias Biológicas y de la Salud, 2014, p. 13-20.

${ }^{9}$ Friedrich Christoph, "The Beginnings of the Industrial Era of Pharmacy”, en Regine Pötzsch (ed.), The Pharmacy Windows on History, Basilea, Roche, 1996. 
ampolletas. ${ }^{10}$ La convergencia de los nuevos medicamentos disponibles y las herramientas tecnológicas necesarias para producirlos a un bajo costo, dio a luz a una nueva y fructífera rama del comercio dedicada a la producción masiva de medicamentos: la industria farmacéutica.

En el caso de México, este proceso no se daría hasta bien entrado el siglo xx. ${ }^{11}$ En el periodo en estudio, la regulación farmacéutica en el país era escasa, lo cual entorpeció el ejercicio profesional y generó descontento entre los farmacéuticos escolarizados del país que observaban frustrados la competencia desigual entre los numerosos medicamentos de patente importados, y las fórmulas de confección magistral fabricadas por ellos en las boticas. ${ }^{12}$ Estos sucesos modificarían el quehacer de los farmacéuticos en todos los niveles: formación académica, ejercicio profesional y regulación sanitaria. ${ }^{13}$

En lo referente a la formación académica, el plan de estudios de la carrera de Farmacia de la ENM contempló una sola cátedra entre 1833 y 1867, la Farmacia Teórico-Práctica, con una duración de dos años, más otros dos

${ }^{10}$ Javier Puerto, “The Apothecary in the 19th Century”, en Regine Pötzsch (ed.), The Pharmacy Windows on History, Basel, Roche, 1996, p. 240.

${ }^{11}$ Godínez y Aceves, Proyectos, realidades y utopías...

${ }^{12} \mathrm{El}$ artículo 4o. de la Carta Magna en 1857 establecía que "todo hombre es libre de abrazar la profesión, industria o trabajo que le acomode". Esto fue interpretado por los farmacéuticos empíricos y otros practicantes de farmacia como una posibilidad para poder ejercer la disciplina sin necesidad de tener un título ni estudios profesionales. A pesar de que la Facultad Médica del Distrito Federal y Territorios vigilaba el ejercicio de la profesión farmacéutica desde 1831, en la realidad no abolió la práctica de boticarios no escolarizados, practicantes de farmacia y charlatanes que ejercían la farmacia sin título profesional ni estudios formales. En 1841 el Consejo Superior de Salubridad reemplazó a la Facultad Médica con la encomienda de visitar y verificar la operación de boticas, almacenes y fábricas de drogas, pero no tuvo capacidad para ejercer acciones punitivas. En 1891 se publicó el primer Código sanitario; éste fue el primer texto regulatorio de alcance nacional; además estaba vinculado a la farmacopea mexicana. El Código, sin embargo, trató con tibieza y ambigüedad el control del ejercicio profesional farmacéutico, situación que fue perpetuada durante casi todo el siglo xx. Mariana Ortiz-Reynoso, Javier Puerto y Patricia Aceves, "La reglamentación del ejercicio farmacéutico en México. Parte i (1841-1902)”, Revista Mexicana de Ciencias Farmacéuticas, v. 39, n. 1, 2008; Mariana Ortiz-Reynoso y Patricia Aceves, "La legislación farmacéutica en México: disposiciones sobre el ejercicio profesional, 1917-1973”, Revista Mexicana de Ciencias Farmacéuticas, v. 45, n. 1, 2014.

${ }^{13}$ Patricia Aceves, "La crisis de la farmacia en México en el cambio de siglo (XIX-XX)", en Francisco Javier Dosil y Gerardo Sánchez (eds.), Continuidades y rupturas. Una historia tensa de la ciencia en México, México, Universidad Nacional Autónoma de México, Instituto de Investigaciones Históricas, 2010; Ortiz-Reynoso y Aceves, "La legislación farmacéutica en México..." 
de práctica en una oficina de farmacia. En 1867 se amplió el currículum a tres materias anuales: Farmacia Teórico-Práctica, Historia Natural de las Drogas Simples y Análisis Químico. Estas cátedras, que también se impartían para los médicos, abordaban diferentes contenidos de química relacionados con la identificación, propiedades, análisis, obtención de preparaciones farmacéuticas y usos terapéuticos de productos naturales y químicos. Con este cambio curricular inició el requisito de presentar una tesis escrita para graduarse de la carrera de Farmacia. ${ }^{14}$ A partir de 1893 la cátedra de Análisis Químico se amplió a dos cursos anuales impartidos en el segundo y tercer año de estudios; ${ }^{15}$ este acontecimiento indica el avance de la química como disciplina coral de la carrera de Farmacia. ${ }^{16}$

En 1908 el plan de estudios volvió a ser modificado con la apertura del curso de Bacteriología que desde años atrás habían solicitado los farmacéu-

${ }^{14}$ Martínez, Aceves y Morales-Cosme, "Una nueva identidad para los farmacéuticos..."

${ }^{15}$ Como se ha mencionado, en el siglo xix europeo los avances en la química permitieron la obtención de fármacos sintéticos y el estudio de los productos aislados de diversas fuentes naturales, favoreciendo el desarrollo de la farmacología experimental. En Europa se modificaron los planes de estudio en diversas universidades para abordar estas áreas emergentes; sin embargo, en México estas novedades no se vieron reflejadas en los programas de estudios de la carrera de Farmacia hasta bien avanzado el siglo xx. Sandra Martínez, Desarrollo y transformación de la farmacia en México (1890-1920), el caso de las primeras mujeres farmacéuticas, tesis de licenciatura en Historia, México, Universidad Nacional Autónoma de México, Facultad de Filosofía y Letras, 2003, p. 150; Josep Simon Communicating Physics: The Production, Circulation and Appropiation of Ganot's Textbooks in France and England, 1851-1887, Londres, Pickering and Chatto, 2011.

${ }^{16}$ A pesar de las carencias del plan de estudios, algunos egresados de Farmacia se desempeñaron como analistas, pues aún no había una escuela de química en esos años y además de los médicos, los profesionales mejor calificados para hacer análisis químicos de muestras biológicas, vegetales, suelos, agua, etcétera, eran los farmacéuticos. Algunos de ellos se establecieron en instituciones gubernamentales como el IMN, los Laboratorios del css y el Laboratorio de Aduanas, y otros en laboratorios privados de análisis clínicos. Estas actividades acusaron la necesidad de reformar el plan de estudios de Farmacia. La tesis de Pedro Peniche López titulada Análisis de las Aguas de Culhuacán (Distrito Federal) describe las carencias del plan de estudios de la ENM y la "necesidad urgentísima que hay de reformar el actual de estudios. Para que nuestra Escuela de Farmacia esté a la altura de las de Europa, como exigen el adelantamiento y cultura á que hemos llegado, necesaria se hace la creación de una cátedra de Análisis Químico de los Vegetales y otra de Química Clínica”. Peniche, citado en Ortiz-Reynoso, Las tesis de Farmacia..., p. 72. Pedro de Lille Borja, otro tesista de Farmacia, señaló que hacían falta estudios de microscopía e histología vegetal, y ambos estudiantes concluyeron que, al ingresar al IMN para hacer un proyecto de investigación, se sentían poco preparados. Ortiz-Reynoso, Las tesis de Farmacia..., p. 54-56. Como veremos adelante, en el periodo estudiado en este trabajo varios tesistas reclaman una reforma a su plan de estudios; entre ellos Esther Luque. 
ticos. Además, se comenzó a ofrecer una asignatura de Legislación Farmacéutica separada de la cátedra de Farmacia Profesional. Este plan dio mayor importancia a las asignaturas de corte práctico, particularmente las enfocadas al estudio de la química. ${ }^{17}$

En 1916 entró en vigor un nuevo plan de estudios para la carrera. Los cursos se volvieron más específicos y los contenidos de química aumentaron. Se añadió un curso de Análisis de Alimentos y Bebidas e Investigaciones Bioquímicas y otro de Química y Legislación Farmacéutica que contaba con una sección dedicada a la toxicología. Un año más tarde, en 1917, el plan de estudios sufrió nuevas modificaciones. La clase de Historia Natural fue dividida en dos cursos anuales, la Bacteriología fue sustituida por una cátedra de Microbiología y se añadió el estudio de la higiene aumentando las horas de práctica. ${ }^{18}$ El cuadro 1 muestra los planes de estudio de 1893, 1908 y 1916 (cuadro 1).

Los cambios curriculares demuestran el creciente interés de los farmacéuticos por especializar, ampliar y profundizar sus conocimientos en química, así como por aplicar los contenidos de sus cátedras a los análisis biológicos, que con el tiempo harían migrar la identidad del profesional farmacéutico hacia estos campos emergentes. En el proceso, la preparación de medicamentos magistrales y oficinales en las farmacias quedó relegada a un segundo plano.

En la era posrevolucionaria, el ámbito académico de los farmacéuticos se vería beneficiado ya que el gobierno apoyó la subsistencia y revitalización de la Universidad Nacional que había sido ideada durante los últimos años del Porfiriato. Como ya se mencionó anteriormente, en 1919 la carrera de Farmacia se escindió de la ENM y se incorporó a la Universidad Nacional de México (UNM) dentro de la Facultad de Química y Farmacia. Este cambio fue el resultado de las acciones promovidas por algunos miembros de la Sociedad Farmacéutica Mexicana entre 1913 y 1918, año en que el rector José Natividad Macías decidió encargar la dirección de la Facultad a la Sociedad Farmacéutica y la subsiguiente incorporación de la carrera de Farmacia. Esta iniciativa formó parte de una estrategia para industrializar las profesiones de farmacia y química y promover el desarrollo de estos sectores

${ }^{17}$ Martínez, Aceves y Morales-Cosme, “Una nueva identidad para los farmacéuticos...”.

${ }^{18}$ La primera tesis de farmacia en la que se llevó a cabo un estudio microbiológico fue el Análisis de las Aguas de Culhuacán (Distrito Federal), escrita por Pedro Peniche López en 1896, Ortiz-Reynoso, Las tesis de Farmacia... Este hecho fue una de las primeras evidencias escritas de la incursión de los farmacéuticos en los análisis microbiológicos. 


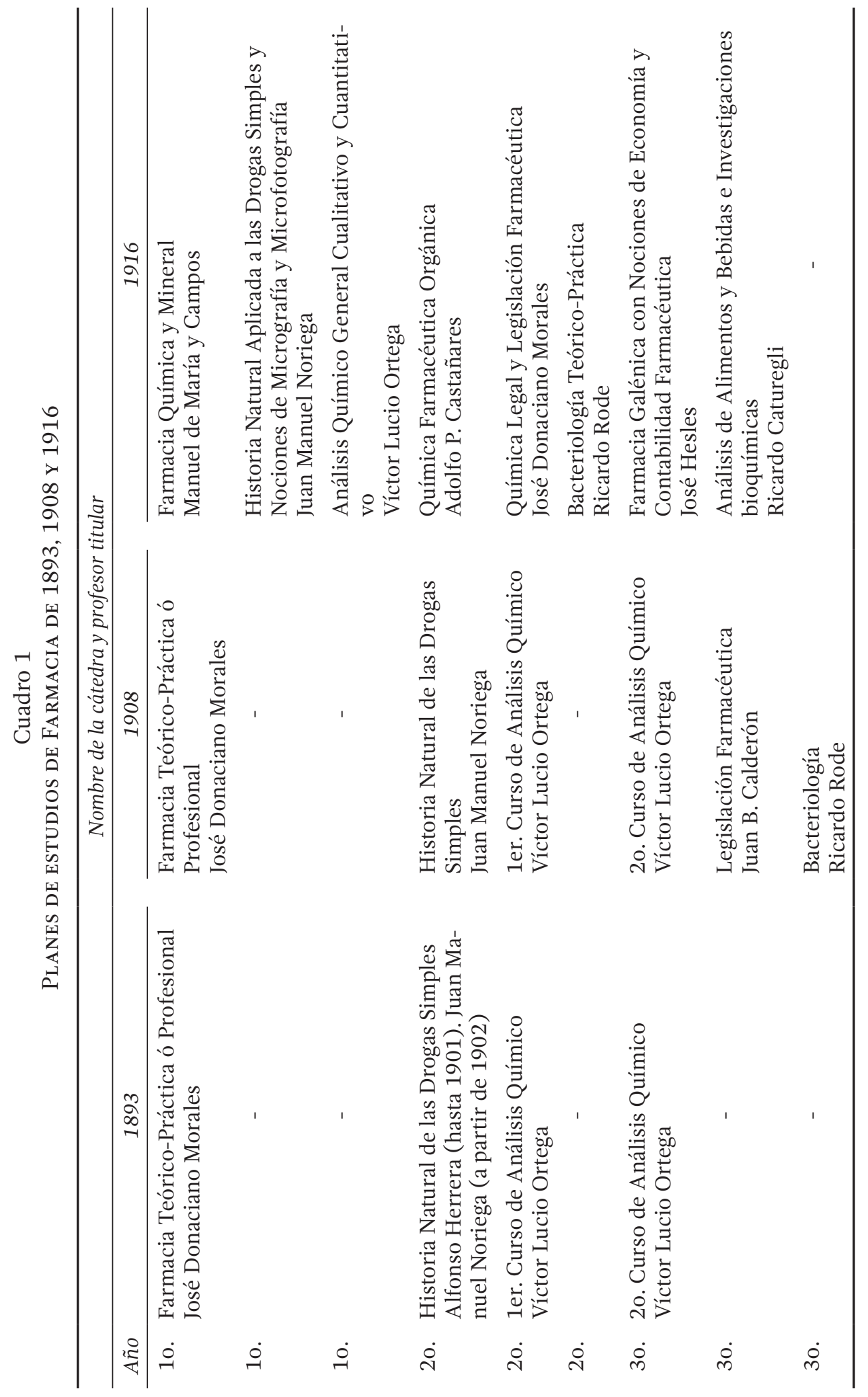


en el país para terminar con la dependencia extranjera. En abril del mismo año el farmacéutico Adolfo P. Castañares asumió la dirección de dicho recinto universitario. ${ }^{19}$ En adelante, la nueva identidad de los farmacéuticos como químicos les permitió tener acceso a la industria química y farmacéutica, así como al terreno de los análisis químicos.

Las asociaciones profesionales también tuvieron un rol destacado en el desarrollo y promoción de la química y la farmacia mexicanas. La Academia Farmacéutica de la capital de la República fue creada por Leopoldo Río de la Loza en 1838 con el objetivo de publicar una farmacopea mexicana, misma que apareció en 1846. Casi tres décadas más tarde, en 1874, la Sociedad Farmacéutica Mexicana (SFM), heredera de esta asociación señera, daría a conocer la segunda edición del texto que sería reeditado periódicamente durante los siguientes cincuenta años. Durante el Porfiriato estas dos agrupaciones, visualizaron el conocimiento científico como un motor para buscar la modernización y el desarrollo del país. A lo largo de este periodo, las páginas de la farmacopea se enriquecieron con las aportaciones de los alumnos de Farmacia que analizaron numerosas plantas medicinales nacionales para incluir su composición química en la sección de Materia Médica del Texto, y que de esta forma pasaran a formar parte del arsenal de medicamentos utilizados en México.

Algunos de los trabajos de análisis químico, se llevaron a cabo en el Instituto Médico Nacional (IMN), una de las instituciones científicas más destacadas durante el Porfiriato, inaugurada en 1888 con la finalidad de estudiar los recursos naturales del país como plantas, animales, aguas y minerales, y de forma especial, aquellos que tuviesen aplicaciones médicas. El objetivo principal del IMN fue la creación de una "terapéutica nacional" que rescatara las plantas indígenas mexicanas. ${ }^{20} \mathrm{El}$ instituto estaba constituido por cinco secciones que trabajaban de forma conjunta: Historia Natural Médica, Química Analítica, Fisiología Experimental, Terapéutica Clínica, Climatología y Geografía Médica.

Particularmente, la Sección de Química Analítica era la encargada de caracterizar muestras de suelos, aguas, plantas y minerales, entre otras. Durante el periodo de estudio de este trabajo, esta sección recibió numerosos

${ }^{19}$ Martínez, Desarrollo y transformación de la Farmacia en México...

${ }^{20}$ Nina Hinke, El Instituto Médico Nacional. La política de las plantas y los laboratorios a finales del siglo XIX, México, Instituto Politécnico Nacional, Centro de Investigación y de Estudios Avanzados/Universidad Nacional Autónoma de México, 2012. 
tesistas de la ENM para realizar los análisis químicos de distintos sustratos. En 1901 la Secretaría de Fomento instruyó al IMN para que incluyera en sus trabajos un enfoque industrial. Asimismo, orquestó una mayor intervención de la institución en la producción y distribución de los "medicamentos nacionales”, llamados así porque provenían de plantas mexicanas o cultivadas en México. Como resultado de la iniciativa, se inauguró en 1904 el Departamento de Química Industrial, el cual amplió los espacios para la investigación y se vio favorecido con la instalación de nuevos equipos. El Departamento fue un espacio único donde estudiantes y profesores enriquecieron sus conocimientos sobre química farmacéutica industrial antes de la fundación de la Facultad de Química. ${ }^{21}$

Con el estallido revolucionario llegó un cambio en la estructura académica y científica del país. La administración revolucionaria desestimó la misión científica del IMN y el trabajo de investigación sobre los recursos terapéuticos de la flora nacional quedó truncado en 1915 con el cierre de la institución. Desafortunadamente, este abrupto final se dio justo en un momento cuando el IMN se disponía a aprovechar los resultados obtenidos por el Departamento de Química Industrial con miras a escalar su producción a nivel industrial. ${ }^{22}$ Es importante destacar que la mayoría de los profesores que trabajaban en el instituto también eran docentes en la ENM y en otras instituciones académicas de distintos niveles. Asimismo, se desempeñaban como analistas en los laboratorios del Consejo Superior de Salubridad y participaban en diversas instancias gubernamentales como peritos o expertos, algunos de ellos también eran dueños de una farmacia o tenían una industria propia. En esos años era común entre las personalidades académicas importantes desempeñar varios empleos al mismo tiempo ya que no existía la figura de investigador de tiempo completo. A diferencia de Europa, donde se dieron los espacios y las circunstancias

${ }^{21}$ Liliana Schifter, Angélica Morales-Sarabia y Patricia Aceves, "La farmacología nacional y la farmacopea mexicana”, Estudios do Século, v. 21, n. 12, 2012.

${ }^{22}$ El objetivo de construir una terapéutica nacional basada en el aprovechamiento de los recursos nacionales no pudo concretarse a nivel industrial, pero los méritos científicos se plasmaron en dos textos de suma importancia histórica: la Farmacología Nacional y los Anales del Instituto Médico Nacional. Además, los investigadores y los tesistas del ImN tuvieron un papel destacado en la fundación de instituciones científicas como la Facultad de Química y el Instituto de Biología de la UNAM, y el Instituto Politécnico Nacional, por mencionar algunas. 
para la aparición de este perfil profesional durante el siglo XIx, en México no aparecería hasta casi mediados del siglo xx. ${ }^{23}$

Como podemos observar, estos especialistas conformaron una red académica-profesional de expertos en análisis químico interesada en ampliar la esfera profesional de los farmacéuticos hacia los campos emergentes de la química. ${ }^{24}$

\section{Resultados}

Entre 1897 y 1919 se encontraron 39 tesis de Farmacia en el Archivo Histórico de la Facultad de Medicina de la unAm. Como ya se ha mencionado, una consecuencia probable del movimiento revolucionario es que trajo consigo una pérdida del registro de las tesis de Farmacia durante siete años (1908-1915), hecho que hoy supone un hueco informativo en el estudio de la historia de la Farmacia mexicana durante el periodo revisado. Un ejemplo es la tesis de Roberto Medellín presentada en 1908 y que hasta hoy no ha podido ser localizada.

El cuadro 2 muestra el listado de las tesis revisadas numeradas en orden cronológico. En adelante haremos referencia a las tesis indicando este número entre paréntesis.

En general, la extensión de los textos revisados oscila entre las 12 y las 35 páginas y su estructura comprende una dedicatoria y/o un discurso dirigido al jurado junto con los resultados de la investigación. Todos los documentos están escritos a máquina en alguna oficina tipográfica de la ciudad de México.

Entre la bibliografía citada se encuentran los textos de los autores europeos más utilizados en el país durante la época: Soubeiran, Bouchardat, Rousseau, Parmentier, Dorvault, Androuard, Dechambre, Femy, Liebig, Scheele, Cavendish, Lavoisier y Van Helmont. Los trabajos también hacen referencia a la Farmacopea Mexicana y citan algunas de sus monografías, aunque las referencias a los trabajos de científicos mexicanos en general son pocas. Las que hay, mencionan las aportaciones experimentales (técnicas y equipos de

${ }^{23}$ Rudolf Stichweh, "Differentiation of Scientific Disciplines: Causes and Consequences", en Encyclopedia of Life Support Systems, Paris, UnEsco, 2003; Liliana Schifter y Patricia Aceves, "Los farmacéuticos y la química en México (1903-1919): prácticas, actores y sitios", Estudios de Historia Moderna y Contemporánea de México, n. 51, 2016.

${ }^{24}$ Aceves, "La crisis de la farmacia en México..." 
laboratorio) de los profesores más que su obra escrita. Destacan los agradecimientos de los estudiantes a los profesores José Donaciano Morales, Víctor Lucio Ortega y Juan Manuel Noriega. Otros nombres que aparecen referenciados en los trabajos son: Juan B. Calderón, destacado farmacéutico a cargo de la botica del Hospital de Jesús, colaborador del Imn y editor de la Farmacopea Mexicana, quien llegaría a ser el presidente de la Sociedad Farmacéutica Mexicana, y José M. Lasso de la Vega, miembro fundador de la Academia Farmacéutica de la capital de la República y de la SFM y editor de la Farmacopea Mexicana por 30 años. En otros trabajos se menciona a destacados farmacéuticos del IMN como Fernando Altamirano, primer director de la institución; Francisco Río de la Loza, director de la Sección de Química Analítica; Alejandro Uribe; Ricardo Caturegli, y Mariano Lozano y Castro. Completan la lista Federico Villaseñor, Ezequiel Pérez, Faustino Roel, Manuel Cordero, Manuel Urbina, James McConnell Sanders, Alfonso Herrera, Francisco Bustillos y Andrés Almaraz, la mayoría de ellos también farmacéuticos en activo en diversas instituciones públicas y privadas. ${ }^{25}$

En cuanto al lugar de realización de las tesis, 13 de los 39 (30\%) documentos estudiados hacen referencia explícita al IMN como uno de los sitios donde los alumnos realizaron parte de su trabajo. Sin embargo, se sospecha de que pudieran ser algunas más debido a la frecuencia con la que en otras tesis se hace referencia a algunos integrantes de esta institución y al tipo de trabajo realizado. El hallazgo no es sorprendente; el vínculo entre los profesores de la ENM y el IMN ya ha sido señalado en numerosas publicaciones. ${ }^{26}$ Otras instituciones mencionadas en los trabajos son: el Instituto Científico Literario del Estado de México (1), ${ }^{27}$ el Hospital de San Andrés (12), ${ }^{28}$ el Instituto Geológico Nacional (35), ${ }^{29}$ la Botica del Hospital de

${ }^{25}$ Liliana Schifter y Angélica Morales-Sarabia, "La trayectoria de Francisco Río de la Loza en la Sección de Química Analítica del Instituto Médico Nacional”, Revista Mexicana de Ciencias Farmacéuticas, v. 43, n. 4, 2012, p. 69-78.

${ }^{26}$ Schifter y Aceves, "Los farmacéuticos y la química...; Martínez, Aceves y Morales-Cosme, "Una nueva identidad para los farmacéuticos..."; Hinke, El Instituto Médico Nacional...; Angélica Morales-Sarabia y Mariana Ortiz-Reynoso, "Research on Psychoactive Plants at Mexico's National Medical Institute, 1888-1915”, Circumscribere, n. 16, 2015.

27 Tesis de Farmacia de Ramón Díaz López, Breves apuntes para el juicio crítico del artículo vinos, Ciudad de México, 1900, en unam, Archivo Histórico de la Facultad de Medicina, Fondo Escuela de Medicina y Alumnos (AHFM-FEMYA), exp. 1, leg. 66.

${ }^{28}$ Tesis de Farmacia de Miguel de Maria y Campos, El formol y sus derivados, Ciudad de México, 1897, unAm, AHFM-FEMYA, exp. 28, leg. 67.

${ }^{29}$ Tesis de Farmacia de Guillermo López, Estudio de algunas obsidianas, Ciudad de México, 1906, UNAM, AHFM-FEMYA, exp. 6, leg. 73. 


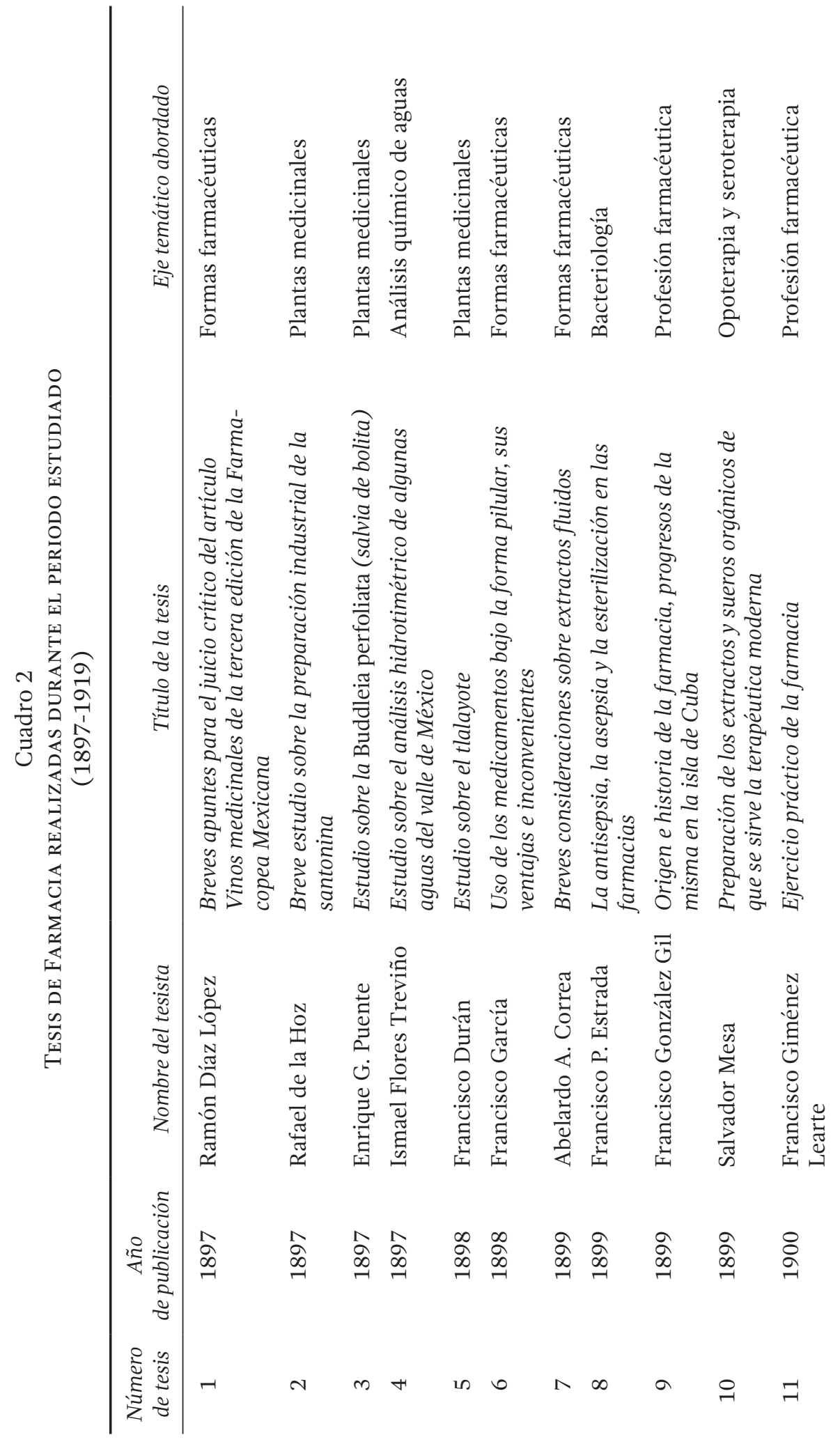



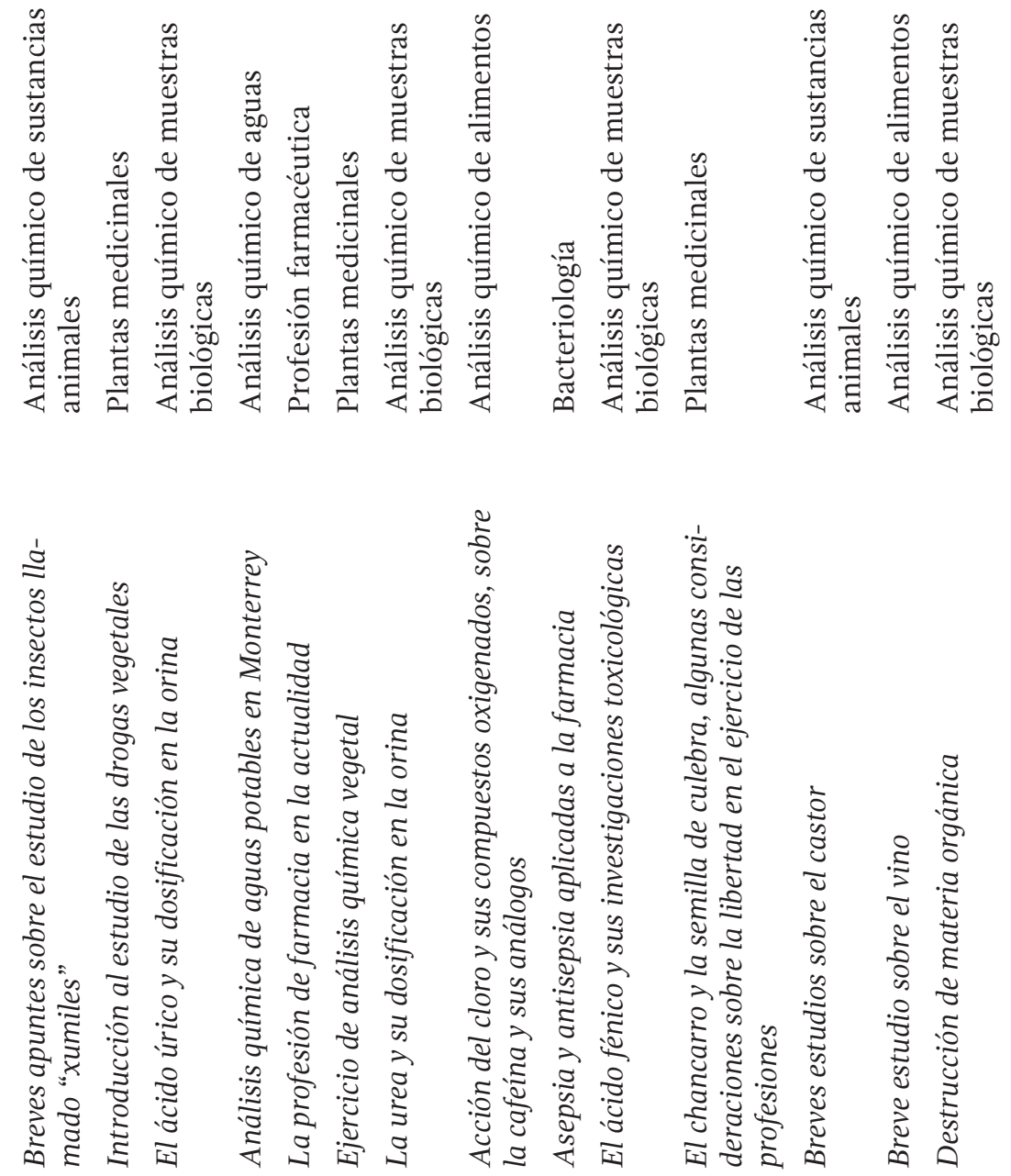

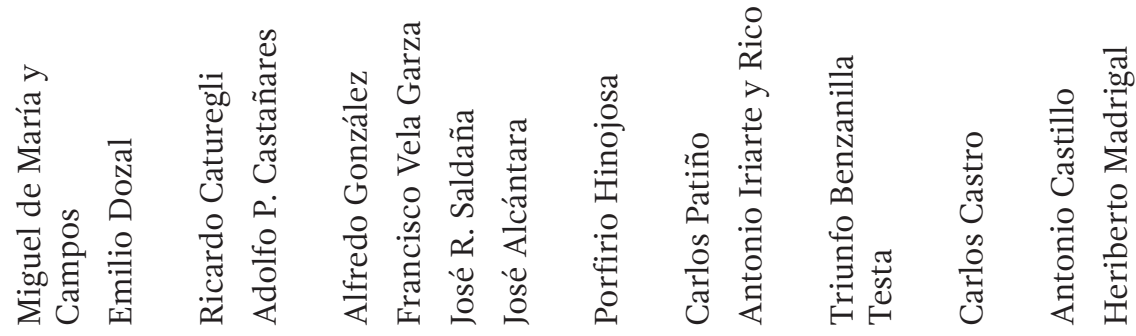

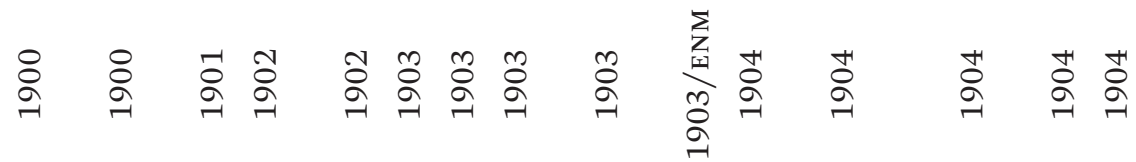

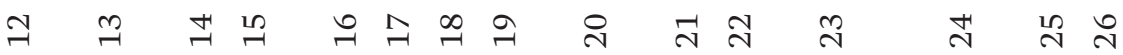




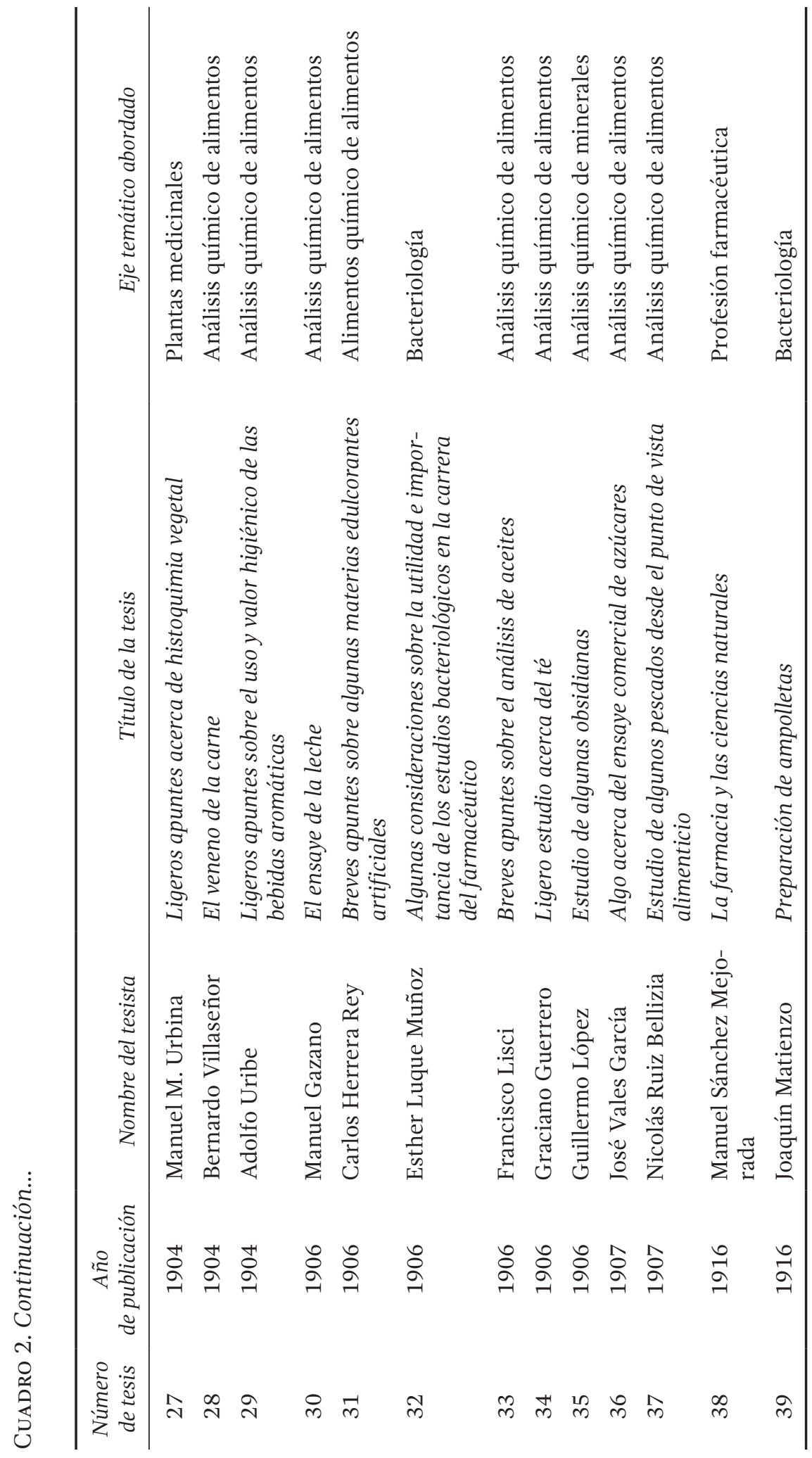


Jesús $(1,10),{ }^{30}$ la Compañía Hidrográfica del Valle de México (4), ${ }^{31}$ la Farmacia Bustillos (3) $)^{32}$ y el Botiquín de la Cárcel Municipal (1).

Es interesante señalar que seis de los trabajos $\left(13,{ }^{33} 17,{ }^{34} 18,{ }^{35} 20,{ }^{36} 25^{37}\right.$ y $31^{38}$ ) fueron realizados por alumnos que estaban inscritos en el Colegio Militar o eran practicantes en el mismo. El hecho de que algunos profesores de la ENM también impartieran clases en dicha instancia parece indicar que los tesistas del Colegio Militar realizaban el trabajo experimental en la ENM, donde tenían acceso a los instrumentos y equipos de laboratorio de dicha institución. Entre los profesores de la ENM que impartieron clase en el Colegio Militar podemos contar al farmacéutico Andrés Almaraz, quien es mencionado por los alumnos en varias de las tesis y años después, a Adolfo P. Castañares, futuro director de la Facultad de Ciencias Químicas y Farmacia. ${ }^{39}$

Como parte del análisis realizado, las 39 tesis se dividieron en diez ejes temáticos construidos a partir de las similitudes de su objeto de estudio, las actividades profesionales relacionadas con éste y la metodología de investigación empleada por los tesistas. Los ejes temáticos develan las líneas de investigación desarrolladas en la ENM y el IMN donde prevalece el interés por el análisis químico de muestras diversas (alimentos, agua, animales, minerales y plantas del territorio nacional): el 61\% de las tesis (24 de las

${ }^{30}$ Tesis de Farmacia de Salvador Mesa, Preparación de los extractos y sueros orgánicos de que se sirve la terapéutica moderna, Ciudad de México, 1899, unAm, AHFM-FEMYA, exp. 45, leg. 69.

${ }^{31}$ Tesis de Farmacia de Ismael Flores Treviño, Estudio sobre el análisis hidrotimétrico de algunas aguas del valle de México, Ciudad de México, 1897, UNAM, AHFM-FEMYA, exp. 53, leg. 65.

${ }^{32}$ Tesis de Farmacia de Enrique G. Puente, Estudio sobre la Buddleia perfoliata, Ciudad de México, 1897, unAm, AHFM-FEMYA, exp. 92, leg. 67.

${ }^{33}$ Tesis de Farmacia de Emilio Dozal, Estudio de los insectos llamados “xumiles", Ciudad de México, 1900, unAm, AHFM-FEmya, exp. 55, leg. 66.

${ }^{34}$ Tesis de Farmacia de Francisco Vela Garza, La profesión de Farmacia en la actualidad, Ciudad de México, 1903, unAm, AHFM-FEmya, exp. 69, leg. 70.

35 Tesis de Farmacia de José R. Saldaña, Ejercicio de análisis química vegetal, Ciudad de México, 1903, unAm, AHFM-FEmya, exp. 28, leg. 71.

${ }^{36}$ Tesis de Farmacia de Porfirio Hinojosa, Acción del cloro y sus compuestos oxigenados, sobre la cafeína y sus análogos, Ciudad de México, 1903, unAm, AHFM-FEmYA, exp. 6, leg. 71.

${ }^{37}$ Tesis de Farmacia de Antonio Castillo, Breve estudio sobre el vino, Ciudad de México, 1904, UNAM, AHFM-FEMYA, exp. 52, leg. 72.

${ }^{38}$ Tesis de Farmacia de Carlos Herrera Rey, Breves apuntes sobre algunas materias edulcorantes artificiales, Ciudad de México, 1906, unAM, AHFM-FEMYA, exp. 128, leg. 72.

${ }^{39}$ Otro personaje mencionado en las tesis es el farmacéutico mayor Manuel Cordero, activo colaborador de la Sociedad Farmacéutica Mexicana y autor de numerosos artículos relacionados con discusiones sobre legislación farmacéutica mexicana publicados en la revista La Farmacia durante las primeras décadas del siglo xx. 
39) se relacionan con el análisis químico. El cuadro 3 muestra el número de trabajos en cada eje y cada año, indicando el número de tesis asignado en el cuadro 1 y el año en el que fueron realizados.

Esta tabla permite observar algunas tendencias en el surgimiento y frecuencia de los temas abordados a lo largo del tiempo. A partir de 1903, numerosos trabajos fueron dedicados específicamente al análisis de alimentos, compuestos químicos y fluidos biológicos en concordancia con las modificaciones al plan de estudios de Farmacia que ampliaron los contenidos del curso de Análisis Químico. Entre 1903 y 1907, diez de las 39 tesis estuvieron dedicadas a este tema. Por otra parte, en 1904 se publicaron las últimas tesis sobre plantas medicinales. Otras temáticas recurrentes incluyen el estudio de las formas farmacéuticas, el ejercicio farmacéutico en las farmacias y algunos contenidos sobre historia y legislación farmacéutica.

Como se ha visto, el IMN fue fundamental para la agenda de investigación del país en el área farmacéutica durante el cambio de siglo; uno de sus propósitos principales fue la comparación directa entre las características terapéuticas de los especímenes animales, minerales y vegetales de origen nacional, con los de origen extranjero para buscar sucedáneos y abatir costos. Precisamente en este sentido las tesis de Farmacia buscaban demostrar que los ejemplares mexicanos eran similares o incluso superiores terapéuticamente a sus contrapartes extranjeras y por lo tanto podían sustituirlas. La gráfica 1 muestra la distribución porcentual de los temas abordados en las tesis revisadas.

A continuación se describe el contenido de las tesis según los ejes temáticos establecidos.

Análisis químico

Análisis químico de sustancias animales

Las tesis relacionadas con el análisis de sustancias provenientes de animales son únicamente dos. Emilio Dozal (13) describe en su trabajo las propiedades alimenticias y afrodisíacas de los xumiles, a partir de los cuales obtiene diversos extractos por la vía húmeda y la seca. En su tesis, Carlos Castro $(24)^{40}$ aborda el castóreo, un material extraído de las glándulas testiculares

40 Tesis de Farmacia de Carlos Castro, Breves estudios sobre el castor, Ciudad de México, 1904, UNAM, AHFM-FEMYA, exp. 92/81, leg. 72. 


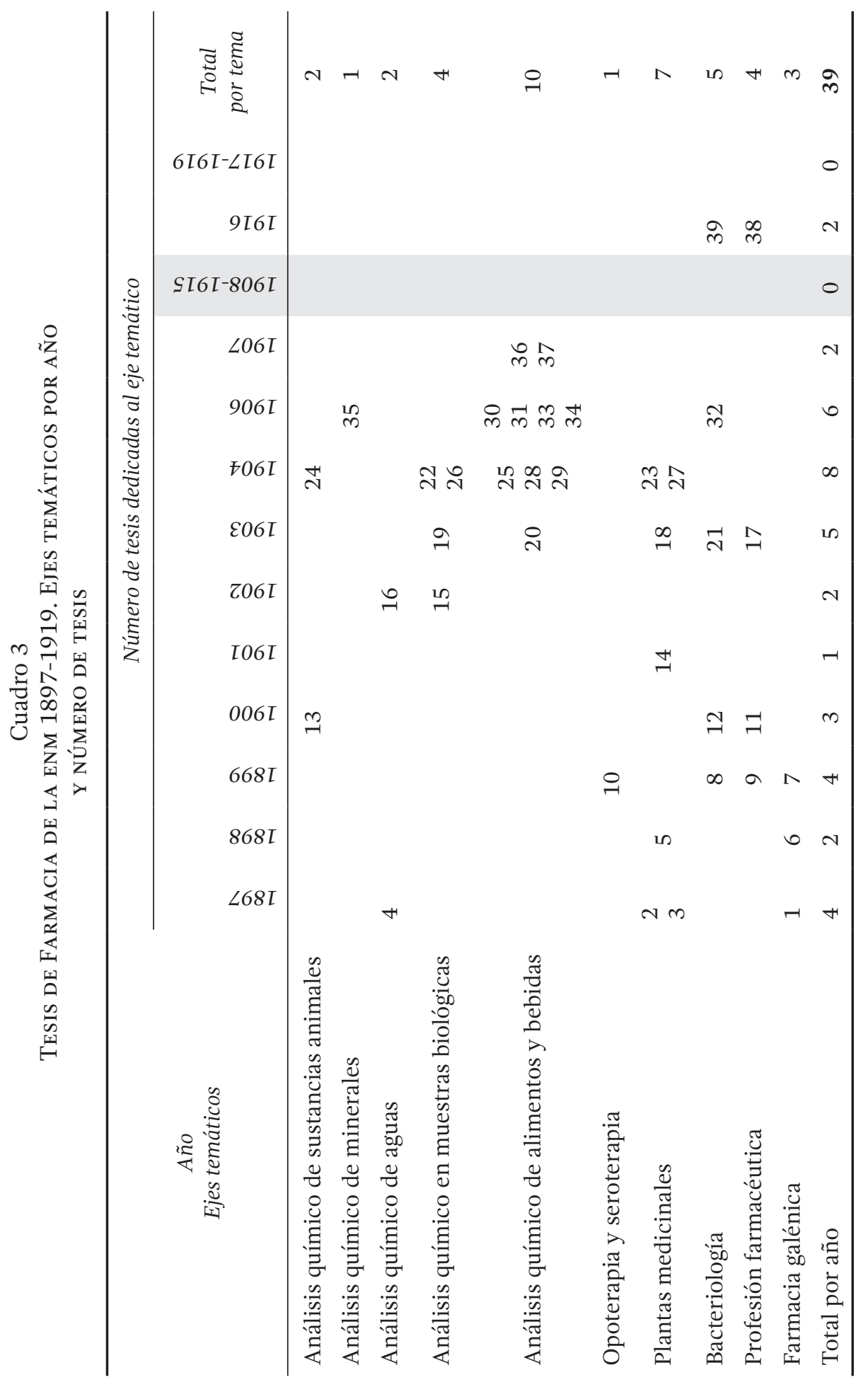




\section{Gráfica 1}

Segmentación de LAS TESIS DE ACUERdo

CON LOS EJES TEMÁTICOS ABORDADOS

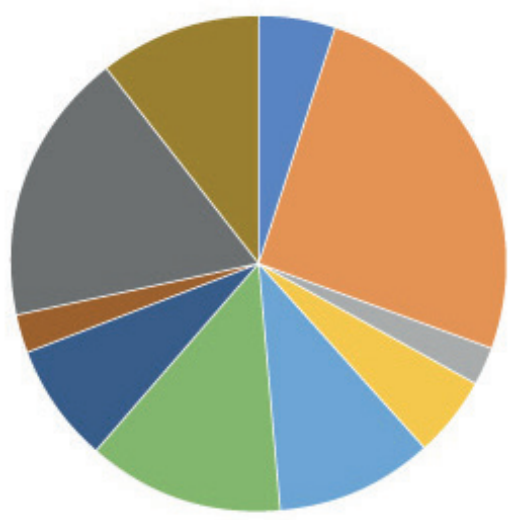

\begin{tabular}{|lcc}
$\begin{array}{l}\text { Ejes } \\
\text { temáticos }\end{array}$ & $\begin{array}{c}\text { Número } \\
\text { de tesis } \\
5.1 \%\end{array}$ & $\begin{array}{c}\text { Formas } \\
\text { farmacéuticas }\end{array}$ \\
\hline Análisis Químico de aguas & $25.6 \%$ & 10 \\
\hline Análisis Químico de alimentos y bebidas & $2.6 \%$ & 1 \\
\hline Análisis Químico de minerales & $5.1 \%$ & 2 \\
\hline Análisis Químico de sustancias animales & $10.3 \%$ & 4 \\
\hline Análisis Químico de muestras biológicas & $12.8 \%$ & 5 \\
\hline Bacteriología & $7.7 \%$ & 3 \\
\hline Farmacia galénica & $2.6 \%$ & 1 \\
\hline Opoterapia y sueroterapia & $17.9 \%$ & 7 \\
\hline Plantas medicinales & $10.3 \%$ & 4 \\
\hline Profesión farmacéutica & & \\
\hline
\end{tabular}

de los castores antiguamente utilizado con fines analgésicos y en el tratamiento de la dismenorrea. Castro hace referencia al castóreo de Canadá, que era el más utilizado en México y que se incluyó entre las monografías de la Farmacopea Mexicana hasta la edición de $1925 .{ }^{41}$ En este trabajo de corte teórico, se describe la composición química de varios tipos de castóreo utilizados en nuestro país.

Estas dos tesis dedicadas al estudio de las aplicaciones médicas de animales continuaron una incipiente corriente de trabajo explorada durante el siglo XIX. El interés por el estudio de las propiedades terapéuticas de los insectos se había manifestado en la ENM durante el siglo XIX con el análisis químico de las cantáridas, de las cuales se extraía cantaridina, una sustancia

${ }^{41}$ Schifter, "Las farmacopeas mexicanas en la construcción de la identidad nacional", Revista Mexicana de Ciencias Farmacéuticas, v. 45, n. 2, 2014, p. 43-54. 
de interés por su actividad vesicante. ${ }^{42}$ A partir del siglo $\mathrm{xx}$, los productos animales se usaron principalmente como excipientes y no como principios activos. Ejemplos clásicos en el mundo son la esperma de ballena, la cera de abejas y el propio castóreo en las cremas dermatológicas.

Análisis químico de sustancias minerales

La única tesis dedicada al estudio de los minerales es la de Guillermo López ${ }^{43}$ (35), ${ }^{44}$ escrita en 1906. El trabajo presenta los resultados del análisis químico elemental y cuantitativo de las obsidianas mexicanas junto con sus características observadas al microscopio. La riqueza histórica de esta tesis se manifiesta en la precisión con la que López expone el método del análisis químico cuantitativo y los aparatos empleados para llevarlo a cabo. Los resultados de este análisis se integraron al estudio de las rocas efectuado por el ingeniero Faustino Roel, director químico del Instituto Geológico Nacional.

Análisis químico de aguas

Las dos tesis que tratan sobre el análisis de aguas fueron presentadas por Ismael Flores Treviño (4) ${ }^{45}$ en 1897 y Alfredo González (16) ${ }^{46}$ en 1902. En ambos trabajos se realiza la caracterización de numerosas muestras de agua en función de tres ejes: potabilidad, composición química y usos (higiénico,

${ }^{42}$ En 1878 Miguel Zúñiga presentó la tesis de farmacia Estudio sobre las cantáridas, en el que cuantifica la cantaridina y verifica si tiene la proporción de alcaloide prescrito en los formularios legales para las preparaciones oficinales. Ortiz-Reynoso, Las tesis de farmacia..., p. 89.

${ }^{43}$ Guillermo López llegaría a destacarse como químico analista en los años siguientes, en 1910 lo encontramos como encargado del gabinete de la clase de Química en la Escuela Nacional Preparatoria y como secretario de la primera Sociedad Química de México establecida en el mismo año. Posteriormente, también sería miembro fundador de la segunda y definitiva Sociedad Química Mexicana establecida en 1926. Schifter y Aceves, "Los farmacéuticos y la química...".

${ }^{44}$ Tesis de Farmacia de Guillermo López, Estudio de algunas obsidianas, Ciudad de México, 1906, unAM, AHFM-FEMYA, exp. 6, leg. 73.

${ }^{45}$ Tesis de Farmacia de Ismael Flores Treviño, Estudio sobre el análisis hidrotimétrico de algunas aguas del valle de México, Ciudad de México, 1897, unAM, AHFM-FEMYA, exp. 53, leg. 65.

${ }^{46}$ Tesis de Farmacia de Alfredo González, Análisis químico de aguas potables en Monterrey, Ciudad de México, 1902, unAm, AHFM-FEmya, exp. 52, leg. 70. 
industrial y alimentario). El trabajo de Ismael Flores analiza muestras de agua provenientes de algunos valles colindantes con la capital del país; es importante mencionar que incluye un análisis bacteriológico e introduce la noción de calidad del agua para su utilización en la fabricación de medicamentos y otras aplicaciones. Por su parte, en la tesis de Alfredo González presentada en 1902 se realiza un análisis químico cuali-cuantitativo mediante una modificación del método hidrotimétrico de Clark para evaluar la utilidad de las muestras de agua como materia prima industrial. La ventaja del método radicaba en su practicidad, ya que permitía establecer de forma rápida y a un bajo costo las características fisicoquímicas del agua en comparación con el análisis químico exhaustivo. Un aspecto innovador del trabajo de González es que utiliza un aparato desarrollado por el doctor Fernando Altamirano (modificado del de Scheibler) para determinar la concentración de gases en las muestras. El equipo referido se muestra en la figura 1.

El estudio de cuerpos de agua de origen natural (pozos, lagos, manantiales, ríos, etcétera) fue prioritario durante el siglo XIX. En la ENM se desarrollaron numerosas tesis de Farmacia sobre este tema, mientras que el IMN también dedicó cuantiosos recursos al análisis de muestras provenientes de mantos acuíferos de toda la República. ${ }^{47} \mathrm{~A}$ diferencia de las tesis escritas en el siglo XIX, en las que el objetivo del análisis químico había sido determinar la utilidad terapéutica de las diversas aguas minerales, ${ }^{48}$ a la vuelta del siglo el interés estuvo centrado en conocer la potabilidad de dichos cuerpos de agua para su consumo humano y sus posibles aplicaciones en la fabricación de medicamentos líquidos y productos alimenticios. En este sentido el análisis bacteriológico de las muestras acuosas cobraría un papel fundamental para dictaminar su viabilidad.

Análisis químico de muestras biológicas

Las características fisicoquímicas y la concentración de distintos compuestos en los fluidos biológicos también fueron objeto de estudio durante este periodo, en especial la urea y el ácido úrico en la orina. Hubo dos tesis que

\footnotetext{
${ }^{47}$ Liliana Schifter y Patricia Aceves, "The Development of Chemistry at the National Medical Institute, 1888-1915”, Circumscribere, 2015, v. 16, p. 46.

${ }^{48}$ Ortiz-Reynoso, Las tesis de farmacia...
} 


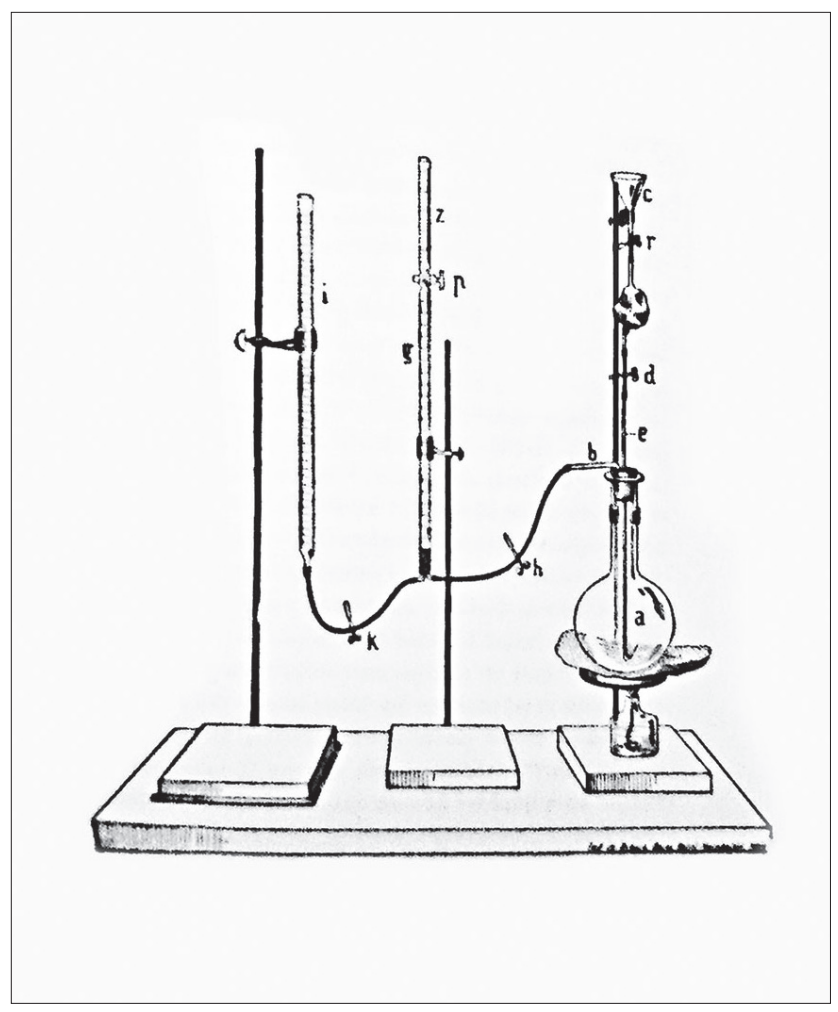

Figura 1. Aparato de Altamirano para dosificar gases en agua, extraído de la tesis de Alfredo González ${ }^{49}$

abordaron esta temática: la de Adolfo P. Castañares (15) ${ }^{50}$ presentada en 1902, y la de José Alcántara (19) ${ }^{51}$ en 1903. La figura 2 muestra la portada de la tesis de Adolfo P. Castañares.

La tesis de Castañares describe brevemente el descubrimiento de la urea, su obtención a partir del guano y los métodos de Heintz, de Haycraft y Denigés para determinar la concentración de esta molécula en la orina. A pesar de que su trabajo es de tipo teórico, es una revisión extensa y meticulosa e incluye las fórmulas químicas desarrolladas de los diferentes

${ }^{49}$ Tesis de Farmacia de Alfredo González, Análisis químico de aguas potables en Monterrey, Ciudad de México, 1902, p. 2, unAm, AHFM-FEmya, exp. 52, leg. 70.

${ }^{50}$ Tesis de Farmacia de Adolfo P. Castañares, El ácido úrico y su dosificación en la orina, Ciudad de México, 1902, unAm, AHFM-FEmya, exp. 1, leg. 66.

${ }^{51}$ Tesis de Farmacia de José Alcántara, La urea y su dosificación en la orina, Ciudad de México, 1903, unAm, AHFM-FEMYA, exp. 1, leg. 66. 


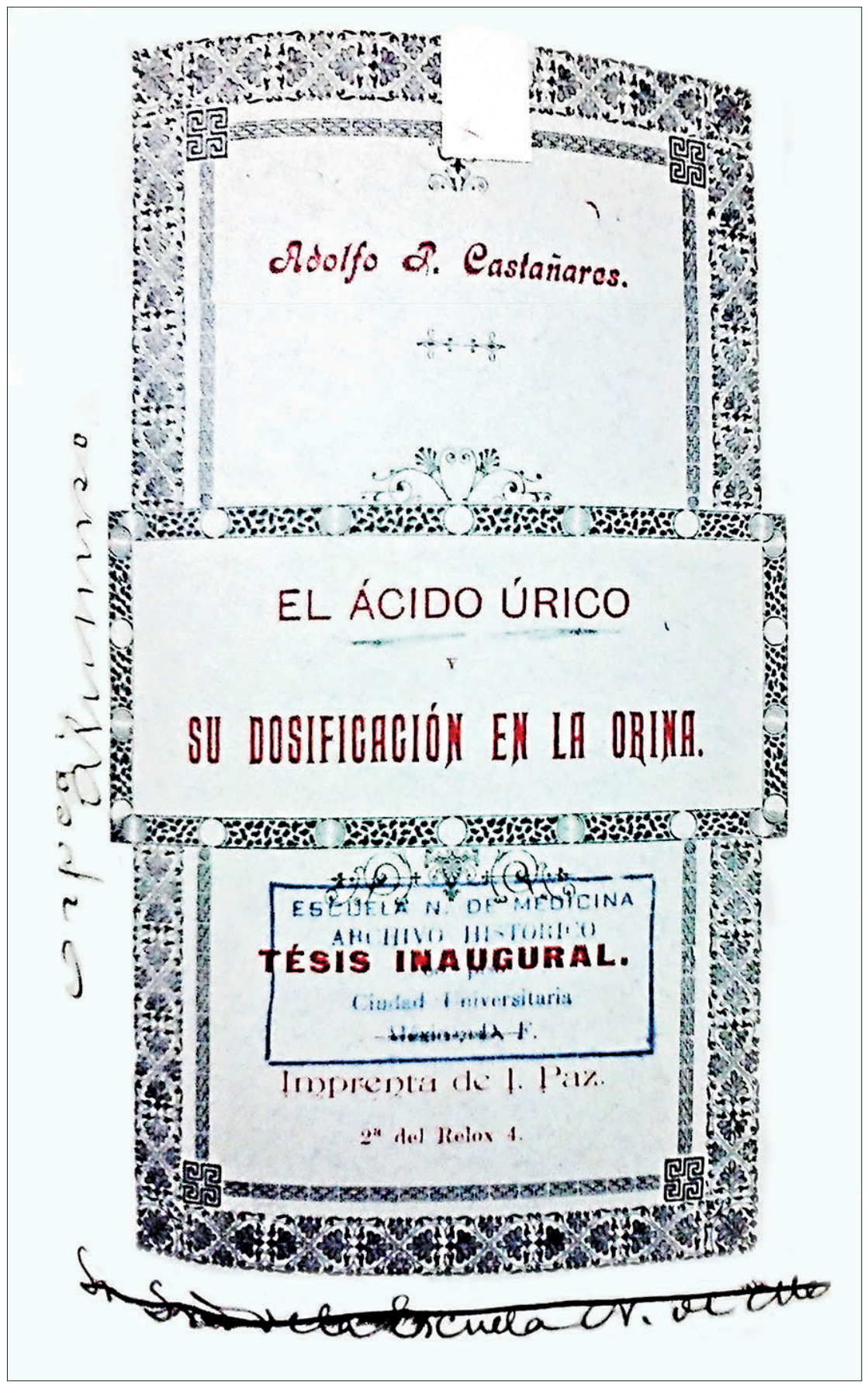

Figura 2. Portada de la tesis de Adolfo P. Castañares 
compuestos orgánicos que intervienen en la síntesis del ácido úrico. ${ }^{52} \mathrm{La}$ tesis de Alcántara hace lo propio con la urea.

Por otra parte la tesis de Antonio Iriarte y Rico (229), ${ }^{53}$ escrita en 1903, aborda cuestiones toxicológicas al proponer una reacción para detectar el ácido fénico en muestras de orina como resultado de un envenenamiento. El trabajo de Heriberto Madrigal (26) ${ }^{54}$ presentado el mismo año, también hace referencia a la toxicología al describir métodos de destrucción de materia orgánica para el análisis de muestras biológicas en estudios forenses.

Estos temas son novedosos para su época, si se considera que la cátedra de Química Legal y Legislación Farmacéutica se inauguró para la carrera de Farmacia hasta 1916. La clase fue impartida por José Donaciano Morales y en ella se estudiaban tópicos de toxicología y análisis forense. Desde 1876 Morales fue experto y analista del Consejo Superior de Salubridad y fue reconocido públicamente por sus estudios médico-legales y toxicológicos realizados para esclarecer fraudes, delitos y envenenamientos en el ámbito personal, de negocios y aduanal. ${ }^{55}$ En este sentido, es válido suponer que haya puesto sus conocimientos y recursos al alcance de sus alumnos tiempo antes de que se inaugurara la cátedra.

Análisis químico de alimentos y bebidas

El análisis de alimentos y bebidas fue uno de los temas más populares entre los alumnos, con un total de diez tesis. Los trabajos están enfocados

${ }^{52}$ Tras su titulación, Castañares viajó a Europa donde obtuvo el grado de doctor en el Instituto Químico de la Real Universidad de Berlín y a su regreso se reincorporó a la Escuela Nacional Preparatoria (ENP) como preparador de las clases de química y posteriormente profesor interino. Por estos años también fue profesor de química general en el Colegio Militar. Hacia 1910 ya era el profesor titular de la clase de Química en la ENP y presidente de la ya mencionada primera Sociedad Química de México inaugurada el mismo año. Posteriormente fue profesor de Química en la Escuela Nacional de Altos Estudios y en 1919 se convertiría en el primer director de la recién inaugurada Facultad de Ciencias Químicas y Farmacia, sin embargo moriría a los pocos meses en forma tristemente prematura. Sus aportaciones a la docencia, la investigación y el servicio le han reservado un lugar destacado en la historia de la química y la farmacia de nuestro país. Expediente de Adolfo P. Castañares, UnAM, AGP, exp. 284.

${ }^{53}$ Tesis de Farmacia de Antonio Iriarte y Rico, El ácido fénico y sus investigaciones toxicológicas, Ciudad de México, 1904, unAm, AHFM-FEmya, exp. 31, leg. 72.

54 Tesis de Farmacia de Heriberto Madrigal, Destrucción de materia orgánica, Ciudad de México, 1904, unAm, AHFM-Femya, exp. 53, leg. 72.

55 Schifter y Aceves, “Los farmacéuticos y la química...”, p. 84. 
principalmente al control de calidad de distintos insumos a partir de la aplicación de pruebas rápidas y sencillas para poner de manifiesto alguna propiedad o molécula específica. Porfirio Hinojosa analiza el contenido de cafeína en distintas plantas con valor alimenticio como el café, mate, guaraná o cacao, por el método colorimétrico (20). Otro ejemplo es el trabajo de Graciano Guerrero, dedicado la cuantificación de teína en muestras de té (34). ${ }^{56}$

Otras investigaciones se basan en la cuantificación de alcohol como indicativo de la calidad del vino medicinal (25) y algunas bebidas aromáticas (29); ${ }^{57}$ también se analizan los aceites comestibles como el de oliva, ajonjolí, algodón y aguacate, a partir de pruebas fisicoquímicas como densidad, color y $\mathrm{pH}$ con el propósito de asegurar la identidad y la calidad de dichos productos y evitar falsificaciones. Un ejemplo es la tesis de Francisco Lisci (33). ${ }^{58}$

Por otra parte, se analizan algunos alimentos como carne, leche y pescado. En el caso de la carne, Bernardo Villaseñor propone un método para determinar la frescura de la misma y evitar intoxicaciones (28). ${ }^{59}$ Nicolás Ruiz propone determinar la presencia de sustancias indicativas del inicio del proceso de putrefacción del pescado (37). ${ }^{60}$ Manuel Gazano plantea determinar las cantidades de caseína, lactosa y sales en la leche de vaca mexicana para asegurarse de que cumple con los criterios requeridos por

56 Tesis de Farmacia de Graciano Guerrero, Ligero estudio acerca del té, Ciudad de México, 1906, UNAM, AHFM-FEMYA, exp. 25, leg. 72.

57 Tesis de Farmacia de Adolfo Uribe, Ligeros apuntes sobre el uso y valor higiénico de las bebidas aromáticas, Ciudad de México, 1904, unAm, AHFM-FEMYA, exp. 1, leg. 66.

${ }^{58}$ Francisco Lisci fue miembro fundador de la primera Sociedad Química Mexicana en 1910, también fue profesor en la Facultad de Química y Farmacia y director de la misma a la muerte de Castañares en 1919. Trabajó en la subcomisión de Productos Químicos de la Farmacopea Mexicana de 1925 junto con Guillermo López y Carlos Herrera Rey y hacia 1926 lo encontramos como presidente de la primera mesa directiva de la segunda Sociedad Química Mexicana. Andoni Garritz y José Luis Mateos, Historia de la Facultad de Química de la Universidad Nacional Autónoma de México. Su primer siglo: 1916-2016, México, Universidad Nacional Autónoma de México, 2015, p. 195. Tesis de Farmacia de Francisco Lisci, Breves apuntes sobre el análisis de aceites, Ciudad de México, 1906, UnAM, AHFM-FEMYA, exp. 72, leg. 39.

59 Tesis de Farmacia de Bernardo Villaseñor, El veneno de la carne, Ciudad de México, 1904, UNAM, AHFM-FEMYA, exp. 1, leg. 66.

${ }^{60}$ Tesis de Farmacia de Nicolás Ruiz Bellizia, Estudio de algunos pescados desde el punto de vista alimenticio. Análisis, alteración conservación, Ciudad de México, 1907, UNAM, AHFMFEMYA, exp. 64, leg. 73. 
el Consejo Superior de Salubridad (30). ${ }^{61}$ Estos trabajos están claramente dirigidos a implementar pruebas de control de la calidad de estos productos y establecer criterios para asegurar sus propiedades nutritivas.

En 1906 Carlos Herrera Rey propone usos y aplicaciones de los edulcorantes artificiales para mejorar el sabor de algunas bebidas (31), mientras que José Vales García plantea en 1907 métodos de evaluación de distintos azúcares de acuerdo con su contenido de humedad, cenizas, glucosa y sacarosa (36). ${ }^{62}$ Ambos autores hacen referencia a estas pruebas para determinar falsificaciones en dichos productos.

Como en otros ejes temáticos anteriores, estos trabajos precedieron por casi diez años la apertura de la cátedra de Análisis de Alimentos y Bebidas e Investigaciones Bioquímicas impartida por Ricardo Caturegli, ${ }^{63}$ verificada hasta 1916. Desde finales del siglo xıx, los farmacéuticos realizaban análisis de alimentos y bebidas con carácter oficial en los laboratorios del Consejo Superior de Salubridad, del Departamento de Salubridad Pública, y el Laboratorio de Aduanas; de ahí que fuese natural incluir esta materia en la carrera de Farmacia. De hecho, los profesores mencionados en las tesis, como Víctor Lucio, Fernando Altamirano, Alejandro Uribe, James McConnell Sanders y Fernando Luna, eran químicos inspectores de alimentos y bebidas en estas instituciones. Lo anterior indica que estos profesores impulsaron los trabajos de sus alumnos en este campo de la química analítica mucho antes de que su estudio formara parte de los contenidos formales de la carrera.

A partir de la revisión de las tesis relacionadas con las diversas modalidades del análisis químico realizadas por los alumnos de la ENM, es claro que la profesión farmacéutica sufrió una drástica evolución en el aspecto educativo durante esta etapa. El predominio temático de las técnicas ana-

${ }^{61}$ Tesis de Farmacia de Manuel Gazano, El ensaye de la leche, Ciudad de México, 1906, UNAM, AHFM-FEMYA, exp. 33, leg. 72.

${ }^{62}$ Tesis de Farmacia de José Vales García, Algo acerca del ensaye comercial de azúcares, Ciudad de México, 1907, unAm, AHFM-FEmya, exp. 11, leg. 82.

${ }^{63}$ Ricardo Caturegli Fontes nació en Hermosillo Sonora en 1877. Cursó sus estudios en la ENP y posteriormente se inscribió a la carrera de Farmacia en la ENM. Los primeros registros de su actividad profesional están asociados a su paso por el IMN donde se desempeñó como conservador del herbario en la Sección de Historia Natural. Ricardo Caturegli destacó especialmente por su trabajo como profesor y en el área sanitaria. Formó parte del profesorado de la Escuela Nacional de Altos Estudios (ENAE) junto con Adolfo P. Castañares del cual fue siempre un muy cercano colaborador. Fue director de la Facultad de Química a partir de 1924, luego en 1931 y nuevamente en 1944. Estuvo al frente del Laboratorio Central a partir de 1927 y fue miembro de la Junta de Gobierno de la Universidad Nacional en 1945. Murió en la Ciudad de México en marzo de 1959. Expediente de Ricardo Caturegli Fontes, s. f., UNAM, AGP, exp. 1966. 
líticas nos permite observar cómo la necesidad de los farmacéuticos de incursionar en la industria y en los campos emergentes de la química fue modificando la enseñanza tradicional de la Farmacia en México.

\section{Plantas medicinales}

Las plantas medicinales constituyen el segundo tema más popular sólo precedido por el de análisis químico de alimentos y bebidas. Se localizaron siete tesis de los siguientes autores: Rafael de la Hoz (2) ${ }^{64}$ de 1897, Enrique G. Puente (3) ${ }^{65}$ de 1897, Francisco Durán (5) ${ }^{66}$ de 1898, Ricardo Caturegli $(14)^{67}$ de 1901, José R. Saldaña (18) de 1902, Triunfo Benzanilla Testa (23) ${ }^{68}$ de 1904 y Manuel M. Urbina (27) ${ }^{69}$ de 1904.

El objetivo de algunas de las tesis era extraer los principios activos de plantas mexicanas con actividad terapéutica para posteriormente comparar su potencia con la de sus homólogos europeos. En el caso del estafiate por ejemplo, se obtuvo la santonina, una sustancia utilizada como vermífugo y que demostró tener la misma efectividad que la proveniente de Europa. Otros trabajos tenían un carácter exploratorio, como el caso de la salvia bolita, el tlalayote o el garbancillo, cuya composición química sugería la presencia de posibles principios activos con aplicación en el tratamiento de diversos padecimientos. A este respecto, cabe recordar que algunos tesistas de la ENM se incorporaron a la Sección de Química Analítica del IMN para estudiar las plantas medicinales con la metodología analítica implementada por los profesores que privilegiaba, ante todo, su aplicación terapéutica. Los resultados de sus estudios permitieron incluir algunas plantas

${ }^{64}$ Tesis de Farmacia de Rafael de la Hoz, Breve estudio sobre la preparación industrial de la santonina, Ciudad de México, 1897, unAm, AHFM-FEMYA, exp. 1, leg. 66.

65 Tesis de Farmacia de Enrique G. Puente, Estudio sobre la Buddleia perfoliata, Ciudad de México, 1897, unAm, AHFM-FEmya, exp. 92, leg. 67.

${ }^{66}$ Tesis de Farmacia de Francisco Durán, Estudio sobre el tlalayote, Ciudad de México, 1898, UNAM, AHFM-FEMYA, exp. 77, leg. 65.

${ }^{67}$ Tesis de Farmacia de Ricardo Caturegli, Introducción al estudio de las drogas vegetales, Ciudad de México, 1901, unAm, AHFM-FEmya, exp. 70, leg. 58.

68 Tesis de Farmacia de Triunfo Benzanilla Testa, El chancarro y la semilla de culebra, algunas consideraciones sobre la libertad en el ejercicio de las profesiones, Ciudad de México, 1904, UNAM, AHFM-FEMYA, exp. 96, leg. 72.

69 Tesis de Farmacia de Manuel M. Urbina, Ligeros apuntes acerca de histoquimia vegetal, Ciudad de México, 1904, unAm, AHFM-FEmya, exp. 54, leg. 70. 
nativas como el chancarro, la borraja, el estafiate y la salvia bolita en la Sección de Productos Naturales de la Farmacopea Mexicana de 1904.

Otros trabajos sobre plantas medicinales no se centran en el análisis químico. Tal es el caso de la tesis de Caturegli, que clasifica la materia médica vegetal a partir de textos de naturalistas y botánicos destacados en distintas épocas o el texto de Manuel M. Urbina, que intenta establecer las dosis de los medicamentos en humanos a partir de estudios realizados en palomas. En el ImN, las pruebas terapéuticas realizadas en animales se denominaban estudios farmacológicos y se llevaban a cabo en la etapa previa al tratamiento en pacientes hospitalizados. ${ }^{70}$

A pesar de que las últimas tesis de Farmacia dedicadas al estudio de las plantas medicinales se publicaron en 1904, podemos afirmar que este tópico permaneció como una línea de investigación relevante durante la transición de los siglos XIX y Xx. El aumento de las plantas medicinales incluidas en las farmacopeas hasta 1925 y en los textos publicados por el IMN confirma este hallazgo. ${ }^{71}$ Una de las familias de moléculas más estudiada fue la de los alcaloides debido a su extendido uso médico para el tratamiento de diversas afecciones. La terapéutica de los alcaloides permaneció vigente durante todo el siglo xix y parte del xx hasta que su uso comenzó a ser controlado estrictamente. En México, las técnicas dedicadas a su aislamiento fueron utilizadas posteriormente para extraer principios activos de numerosas plantas que se habían utilizado tiempo atrás en Farmacia. La disponibilidad del fármaco concentrado permitió controlar los niveles de pureza, actividad y concentración de estos productos y generó medicamentos más potentes y eficaces. ${ }^{72}$ En el proceso, las preparaciones magistrales y oficinales dispensadas en las farmacias y fabricadas a partir de partes completas o inclusive extractos totales de plantas medicinales fue disminuyendo drásticamente junto con la necesidad de la presencia de los farmacéuticos en las boticas para prepararlas.

\footnotetext{
${ }^{70}$ Angélica Morales-Sarabia y Mariana Ortiz-Reynoso, "Research on Psychoactive Plants at Mexico's National Medical Institute, 1888-1915”, Circumscribere, n. 16, 2015.

${ }^{71}$ Liliana Schifter, "Las farmacopeas mexicanas en la construcción de la identidad nacional”, Revista Mexicana de Ciencias Farmacéuticas, v. 45, n. 2, 2014.

${ }^{72}$ Mariana Ortiz-Reynoso, "Farmacia química en el siglo xIX mexicano: una mirada a través de los alcaloides”, en Signa Naturalia. Concepciones y prácticas en torno a la materia médica, la farmacia y la salud (siglos XVI-XX), México, Universidad Nacional Autónoma de México, Centro de Investigaciones Interdisciplinarias de Ciencias y Humanidades, 2016.
} 


\section{Bacteriología}

A pesar de que la bacteriología se instituyó como asignatura de la carrera de Farmacia hasta 1908, el interés de los farmacéuticos en este campo surgió con anterioridad, como se refleja en las tesis de Francisco P. Estrada $(8)^{73}$ de 1899 , Miguel de Maria y Campos $(12)^{74}$ de 1900 , Carlos Patiño (21) ${ }^{75}$ de 1903 y Esther Luque Muñoz (32) ${ }^{76}$ de 1906.

Los trabajos anteriores abordan de forma genérica la técnica de la esterilización y el análisis de muestras, y subrayan sus aplicaciones en el área farmacéutica. La tesis de Miguel de Maria y Campos fue elaborada en el Hospital de San Andrés y describe las aplicaciones del formol en la conservación de ejemplares biológicos. El autor apunta que la bacteriología utiliza elementos para mantener el estado aséptico y centra su discusión en el formol, un derivado del formaldehido. La tesis abarca su descubrimiento, los estudios previos, su modo de preparación, derivados e impurezas y describe su poder antiséptico y acción antifermentable.

La tesis de Esther Luque describe exhaustivamente cómo efectuar un análisis microbiológico; detalla las características observables al microscopio, define la asepsia y la antisepsia aplicadas a instrumentos, preparaciones y técnicas, e indica tanto el tipo de personal como el sitio correcto en que deben tratarse los ejemplares microbiológicos. Luque menciona la utilidad de la técnica de la tinción de Gram (publicada en 1884 y vigente en nuestros tiempos) y manifiesta la importancia de la bacteriología para el diagnóstico y el tratamiento del paciente, alertando sobre la falta de farmacéuticos especialistas en el tema. En su trabajo solicita la apertura de una cátedra de Bacteriología para la carrera de Farmacia, acontecimiento que tuvo lugar dos años después de la publicación de su tesis. ${ }^{77}$

73 Tesis de Farmacia de Francisco P. Estrada, La antisepsia, la asepsia y la esterilización en las farmacias, 1899, UNAM, AHFM-FEMYA, exp. 64, leg. 67.

${ }^{74}$ Tesis de Farmacia de Miguel de Maria y Campos, El formol y sus derivados, Ciudad de México, 1900, unAm, AHFM-FEMYA, exp. 28, leg. 67.

75 Tesis de Farmacia de Carlos Patiño, Asepsia y antisepsia aplicadas a la farmacia, Ciudad de México, 1903, unam, AHFm-Femya, exp. 11, leg. 71.

76 Tesis de Farmacia de Esther Luque Muñoz, Algunas consideraciones sobre la utilidad e importancia de los estudios bacteriológicos en la carrera del farmacéutico, Ciudad de México, 1906, UNAM, AHFM-FEMYA, exp. 72, leg. 118.

${ }^{77}$ La asignatura de Bacteriología inaugurada en 1908 introdujo a los alumnos a los estudios de clasificación, caracterización, fisiología e identificación de bacterias, dotándolos 
Por otro lado, la tesis de Joaquín Matienzo (39) ${ }^{78}$ escrita en 1916 denuncia que los métodos de esterilización de las soluciones medicinales eran poco conocidos por los encargados de las boticas y advierte la falta de pericia entre los farmacéuticos del país. Enseguida expone algunos métodos de esterilización de soluciones inyectables, indicando sus ventajas y desventajas.

Hacia ese mismo año, en las boticas mexicanas ya se vendían ampolletas de fabricación nacional y también las que se importaban desde Italia o Francia por empresas extranjeras establecidas en el país. En 1919 Triunfo Bezanilla \& Compañía inició la fabricación masiva de preparaciones estériles, por lo que instaló un laboratorio especializado en este tipo de formas farmacéuticas. ${ }^{79}$

Es importante mencionar que la Farmacopea Mexicana de 1896 y 1904 muestra que los farmacéuticos ya empleaban diversas técnicas de esterilización y asepsia para la preparación de líquidos inyectables de administración subcutánea o hipodérmica; ${ }^{80}$ sin embargo, la esterilización como herramienta para el control de calidad de preparaciones farmacéuticas se incluyó por primera vez en la Farmacopea Mexicana hasta $1925 .{ }^{81}$ Esta edición contó con la colaboración de Esther Luque, que para esas fechas ya era miembro de la SFM. ${ }^{82}$

de habilidades para realizar análisis de orina, esputo y sangre. (Martínez, Desarrollo y transformación de la farmacia...)

78 Tesis de Farmacia de Joaquín Matienzo, Preparación de ampolletas, Ciudad de México, 1916, UNAM, AHFM-FEMYA, exp. 35, leg. 97.

${ }^{79}$ Rogelio Godínez y Patricia Aceves, Proyectos, realidades y utopías...

${ }^{80}$ Sociedad Farmacéutica Mexicana, Nueva farmacopea mexicana, 3a. edición, México, Oficina y Typográfica de la Secretaría de Fomento, 1896, Archivo Histórico de la Farmacopea de los Estados Unidos Mexicanos; Sociedad Farmacéutica Mexicana, Nueva farmacopea mexicana, 4a. ed., México, Oficina Typográfica de la Secretaría de Fomento, Archivo Histórico de la Farmacopea de los Estados Unidos Mexicanos.

${ }^{81}$ Liliana Schifter, Espíritu e identidad farmacéuticos. La construcción de la farmacopea mexicana (1846-2011), México, Universidad Nacional Autónoma Metropolitana-Unidad Xochimilco, 2014.

${ }^{82}$ Esther Luque nació en Pachuca el 10 de diciembre de 1884. Esta notable mujer inició en 1898 los estudios preparatorios en el Instituto Científico y Literario del Estado de Hidalgo, y en 1903 obtuvo el pase de la preparatoria para inscribirse en la Escuela Nacional de Medicina y cursar la carrera de Farmacia. Tres años más tarde, cuando obtuvo el título de Profesora de Farmacia en 1906 se convirtió en la primera farmacéutica mexicana y, posteriormente, también se convertiría en la primera profesora titular en la Escuela Nacional de Ciencias Químicas y la primera mujer en participar de manera profesional en asociaciones como la Sociedad Farmacéutica Mexicana, donde fue editora de la Farmacopea Mexicana y 


\section{Opoterapia y seroterapia}

A finales del siglo XIX, la seroterapia y la preparación de extractos y sueros representaron un avance terapéutico que interesó a los farmacéuticos, quienes poco a poco lograron insertarse en este nuevo campo que iba de la mano de los ensayos clínicos. La tesis de Salvador Mesa, denominada Preparación de los extractos y sueros orgánicos de que se sirve la terapéutica moderna $(10)^{83}$ de 1899 , es la única que aborda este tema, pero es un botón de muestra de este cambio. El trabajo es una extensa revisión de los líquidos biológicos, su origen animal y el modo y precauciones que debe tener su preparación, incluyendo varias técnicas de esterilización y los instrumentos y reactivos necesarios para llevarlas a cabo. Mesa describe la forma en que se conservaban los primeros líquidos orgánicos inyectables y cómo la llegada de las "ampulitas de vidrio" disminuyó la probabilidad de contaminación por gérmenes, pero acusa que en México el consumo de estos productos era bajo.

En una segunda sección aborda la seroterapia, otra rama nueva para la farmacia que consiste en el aprovechamiento del suero con fines terapéuticos. Indica que hay tres formas para la preparación del suero: extracción de sangre humana (suero natural), preparación de un líquido de igual composición química que el suero sanguíneo humano (suero artificial) y obtención de un producto a partir de la inyección gradual de sangre humana enferma o convaleciente en un animal que generará propiedades para curar la enfermedad del paciente (sueros inmunizadores). De estos últimos describe la preparación de sueros antiponzoñosos, tuberculina de Koch, maleína y suero antidiftérico. Asimismo, advierte que tanto la opoterapia como la seroterpaia requieren del estudio de la bacteriología y la anatomía comparada, y se lamenta de que aún no formaran parte del plan de estudios de Farmacia.

En México, el desarrollo de la opoterapia y la seroterapia conduciría eventualmente a la producción de vacunas a gran escala derivada principalmente de las actividades realizadas en el Instituto de Higiene. Hacia mediados de siglo, la investigación realizada en esta institución era

posteriormente miembro de la mesa directiva de la Sociedad Química Mexicana. Martínez, Desarrollo y transformación de la farmacia...; Felipe León-Olivares, "Esther Luque: primera farmacéutica mexicana”, Educación Química, v. 21, n. 2, 2010.

83 Tesis de Farmacia de Salvador Mesa, Preparación de los extractos y sueros orgánicos de que se sirve la terapéutica moderna, Ciudad de México, 1899, unAM, AHFM-FEMYA, exp. 45, leg. 69. 
reconocida mundialmente y la mayor parte de las vacunas empleadas en el país eran fabricadas en territorio mexicano. ${ }^{84}$

\section{Profesión farmacéutica}

Los autores de las cuatro tesis dedicadas a la legislación y el ejercicio farmacéutico son: Francisco González Gil (9) ${ }^{85}$ de 1899, Francisco Jiménez Learte (11) ${ }^{86}$ de 1900, Francisco Vela Garza (17) de 1903 y Manuel Sánchez Mejorada (38) $)^{87}$ de 1916.

El cubano Francisco González Gil describe las tres fuentes principales de la materia farmacéutica: farmacozoología, farmacofitología y farmacoryetología (farmacéutica mineral), y menciona cerca de una decena de formas farmacéuticas comunes en Cuba, destacando los distintos tipos de vinos, jarabes, bálsamos y ungüentos. Reconoce que en Cuba el desarrollo de la ciencia se veía limitado, pero exalta la riqueza en materia farmacéutica de ese país, especialmente de las propiedades expectorantes del tebenque, una planta endémica de la isla. Además, menciona al mexicano doctor José Márquez, quien según el autor se había instalado en Cuba desde hacía sesenta años.

La tesis del español Francisco Jiménez Learte describe los utensilios, los métodos y las medidas necesarios para la elaboración y despacho de los medicamentos, reconociendo la importancia de la limpieza del establecimiento en apego a la farmacopea mexicana. Enseguida define los métodos de división de partículas y de separación de soluciones, y ofrece una explicación de los tipos de mezclas.

Por su parte Francisco Vela Garza da a conocer la situación legal que aquejaba a los farmacéuticos de la ciudad de México, exponiendo el libertinaje profesional existente. Denuncia el contraste regulatorio entre los

${ }^{84}$ Godínez, "Los primeros medicamentos químicos...".

${ }^{85}$ Tesis de Farmacia de Francisco González Gil, Origen e historia de la farmacia, progresos de la misma en la isla de Cuba (Materiales farmacéuticos de dicho país), Ciudad de México, 1899, UNAM, AHFM-FEMYA, exp. 10, leg. 68.

${ }^{86}$ Memoria presentada por el farmacéutico español Francisco Jiménez Learte, Ejercicio práctico de la farmacia, Ciudad de México, 1900, unAm, AHFM-FEmya, exp. 1, leg. 66.

${ }^{87}$ Tesis de Farmacia de Manuel Sánchez Mejorada, La farmacia y las ciencias naturales (Breve consideración sobre la importancia que el estudio de estas ciencias tiene para la farmacia), Ciudad de México, 1916, unAm, AHFM-FEMYa, exp. 1, leg. 66. 
países sudamericanos (que habían firmado un tratado para proteger el ejercicio profesional y la seguridad de los pacientes) y la situación en México, donde se declaraba libre el ejercicio de todas las profesiones. La defensa que plantea Vela Garza del ejercicio profesional no va en el sentido del beneficio de los farmacéuticos sino que está centrada en el paciente: "si nos ponemos a considerar lo delicado que es el servicio farmacéutico y las responsabilidades que acarrea veremos que no es posible poner en las manos de cualquier práctico, la salud o quizá la vida". 88

Por último, la tesis de Manuel Sánchez Mejorada enfatiza la importancia de la química como la ciencia central para la farmacia, seguida de la zoología y la física.

\section{Farmacia galénica}

Los tres trabajos que abordan el tema de las formas farmacéuticas fueron escritos a lo largo de un periodo de 19 años y son los de: Ramón Díaz López $(1)^{89}$ de 1897, Francisco García (6) ${ }^{90}$ de 1898 y el de Abelardo A. Correa (7) ${ }^{91}$ de 1899.

En general, estas tesis describen el método, las condiciones y los utensilios para la elaboración en pequeña escala de algunas formas farmacéuticas como los vinos medicinales, las píldoras y los extractos fluidos. Asimismo enuncian sus propiedades medicinales, sus características físicas y su formulación.

Es frecuente que los autores recomienden ajustes en las técnicas o mejoras a los procesos relacionados con la fabricación de medicamentos. Ramón Díaz López, alumno tanto de la ENM como del Instituto Literario del Estado de México, centra su disertación en los vinos medicinales, comenzando con la exposición de un problema puntual relativo al control de la

88 Tesis de Farmacia de Francisco Vela Garza, La profesión de Farmacia en la actualidad, Ciudad de México, 1903, p. 11, unam, AHFM-FEmya, exp. 69, leg. 70.

89 Tesis de Farmacia de Ramón Díaz López. Breves apuntes para el juicio crítico del artículo vinos medicinales de la tercera edición de la farmacopea mexicana, Ciudad de México, 1897, UNAM, AHFM-FEMYA, exp. 1, leg. 66.

90 Tesis de Farmacia de Francisco García, Uso de los medicamentos bajo la forma pilular, sus ventajas e inconvenientes, Ciudad de México, 1898, unAM, AHFM-FEmya, exp. 10, leg. 67.

${ }^{91}$ Tesis de Farmacia de Abelardo A. Correa, Breves consideraciones sobre extractos fluidos, Ciudad de México, 1899, unAm, AHFM-FEmya, exp. 64, leg. 67. 
calidad de estos productos: la variación en la naturaleza y la calidad provocada por las distintas riquezas o grados de alcohol del vino utilizado para disolver los principios activos, apuntando que "de la variedad de preparación tiene que resultar variedad en la acción terapéutica que puedan tener". ${ }^{92}$ Díaz López propone permitir la adición de alcohol al vino e indicar el grado espirituoso final. Además expone el problema de la conservación o falta de estabilidad de los vinos, derivada de los cambios de "condiciones de clima, presión y temperatura”, que se manifiesta "después de algún tiempo de elaborados", pues "se forman en el seno del líquido depósitos de los principios de las sustancias medicinales, ó bien se verifican combinaciones que dan lugar á productos nuevos". ${ }^{93}$ Cita a Soubeiran, quien recomendaba específicamente el empleo de vino rojo para algunos preparados (como el de opio, en el que la disolución de la narcotina se favorecía por el contenido de taninos), y a Bouchardat, que explicaba que para hacer vino de quina debía emplearse el vino blanco ácido adicionado con alcohol para evitar precipitación de quinina y cinconina.

La tesis de Francisco García describe detalladamente el método, equipo e instrumentos utilizados en la fabricación de las cuatro formas farmacéuticas pilulares: píldoras, bolos, grageas y gránulos. García menciona las malas prácticas seguidas comúnmente y los errores ocasionados como consecuencia; también da recomendaciones para mejorar la fabricación de los medicamentos pilulares y anexa un listado de cerca de 60 sustancias que, ya sea solas o mezcladas, eran de utilidad para la fabricación de estas formas farmacéuticas.

La tesis de Abelardo Correa toma como referencia a la United States Pharmacopoeia para abordar los métodos adecuados para preparar los extractos fluidos, así como los aparatos y técnicas necesarios para dichos procesos. Describe las diferencias en la estabilidad de los extractos dependiendo de su origen y los retos para la verificación de su identidad y pureza.

Vale la pena mencionar la evolución de las formas farmacéuticas a lo largo de las casi dos décadas revisadas. Al principio de este periodo se

92 Tesis de Farmacia de Ramón Díaz López, Breves apuntes para el juicio crítico del artículo vinos medicinales de la tercera edición de la farmacopea mexicana, Ciudad de México, 1897, p. 16, UNAM, AHFM-FEMYA, exp. 1, leg. 66.

${ }^{93}$ Tesis de Farmacia de Ramón Díaz López, Breves apuntes para el juicio crítico del artículo vinos medicinales de la tercera edición de la farmacopea mexicana, Ciudad de México, 1897, p. 17, UNAM, AHFM-FEMYA, exp. 1, leg. 66. 
proyecta la obtención y la formulación de extractos fluidos, vinos medicinales y píldoras, tres formas farmacéuticas muy utilizadas durante la segunda mitad del siglo XIX, mientras que a partir de 1916 se menciona la fabricación de las ampolletas estériles dentro de las farmacias, una forma farmacéutica relativamente novedosa para la época. El desarrollo de las ampolletas se deriva de los trabajos de Louis Pasteur y de diversos científicos que comprendieron la importancia de prevenir la contaminación microbiana en todos aquellos productos farmacéuticos parenterales (es decir, que se administraban mediante inyección en el ser humano y en algunos animales). Estas formulaciones revolucionarían la práctica médica por su eficiencia y seguridad para la prevención y el tratamiento de enfermedades. ${ }^{94}$

\section{DISCUSIÓN GENERAL}

La gran mayoría de las tesis analizadas durante este periodo están relacionadas con el análisis químico de diversos sustratos. Es notable la diversificación en los temas de investigación, representada por nuevos campos como la toxicología, la asepsia o la seroterapia. Aparecen los análisis de las muestras de tejidos biológicos, se reorientan los de agua dejando de lado las aguas minerales terapéuticas y se abordan las aplicaciones de este líquido vital en los servicios sanitarios e industriales (potabilidad, dureza).

El 30\% de los trabajos fueron realizados en el IMN, donde a finales del siglo xix se privilegió el análisis químico de interés médico, y a partir de los primeros años del siglo xx se diversificó hacia el análisis de alimentos y fluidos biológicos enfocados al control de calidad y las aplicaciones clínicas. Asimismo, durante la primera década del siglo xx hay un incremento en las temáticas relacionadas con la toxicología y la bacteriología, especialmente en relación con los productos para consumo humano (alimentos, bebidas y medicamentos). Además del ImN, otras instituciones mencionadas en los trabajos son: el Colegio Militar, el Instituto Científico Literario

${ }^{94} \mathrm{Al}$ respecto, recomendamos revisar el texto de Godínez, Schifter y Ortiz-Reynoso publicado en el número 57 de la presente revista y donde se abordan las particularidades de la introducción de las ampolletas inyectables en nuestro país durante las primeras décadas del siglo xx. Rogelio Godínez, Liliana Schifter y Mariana Ortiz-Reynoso, "Llegada de las ampolletas inyectables a México y Estados Unidos. Diferencias y similitudes en la práctica farmacéutica (1896-1939)", Estudios de Historia Moderna y Contemporánea de México, n. 57, enero-junio 2019. 
del Estado de México, el Hospital de San Andrés, el Instituto Geológico Nacional, la Botica del Hospital de Jesús, la Compañía Hidrográfica del Valle de México, la Farmacia Bustillos y el Botiquín de la Cárcel Municipal. Estos datos muestran la red de profesores, investigadores y profesionales farmacéuticos con los que se asociaban los farmacéuticos de la ENM.

A pesar de que el número de trabajos relacionados con el tema de las formas farmacéuticas es limitado, las tesis dedicadas a su estudio permiten observar un cambio en el tipo de medicamento elegido para administrar un fármaco y en los criterios aplicados a la selección de excipientes, procesos de elaboración y vías de administración. En el periodo estudiado coexisten los vinos medicinales, los extractos fluidos y las píldoras (18971899) con las ampolletas (1916), anunciando así la transición de las formas magistrales a las oficinales. Asimismo aparecen los conceptos de identidad y pureza, calidad y exactitud de dosis (concentración en los extractos) y se presta mayor atención al desempeño de los excipientes en las formas farmacéuticas terminadas; esto denota una transición desde la farmacia galénica, tímidamente representada por algunas formas farmacéuticas propias del siglo XIX, hacia las aplicaciones industriales de la ciencia química en la farmacia que se desarrollarían en el siglo xx. Sin embargo, es importante subrayar que ninguno de los trabajos revisados hace referencia a la industria farmacéutica. No hay menciones directas a la colaboración de los alumnos con ninguna institución privada o pública relacionada con actividades industriales y por lo tanto es difícil hacer una valoración acerca del grado de desarrollo de dicho sector en el periodo estudiado a través de estos textos.

\section{CONCLUSIONES}

Los estudios publicados previamente demuestran que durante las últimas tres décadas del siglo xıx mexicano la profesión farmacéutica sufrió una crisis identitaria provocada por tres factores principales: la inestabilidad política y económica del país, la entrada desmesurada de específicos o medicamentos de patente extranjeros y la falta de reglamentación sanitaria en materia de ejercicio farmacéutico. El análisis de las tesis de Farmacia escritas de 1897 a 1919 indica que a la vuelta del siglo se verificó un cambio en el objeto de estudio de los farmacéuticos escolarizados, que fue desde la composición química de los productos medicinales (especialmente plantas 
y aguas minerales) hacia la microbiología y el análisis químico de alimentos y productos biológicos. Asimismo, se puede observar que inicia la migración de las preparaciones magistrales y oficinales fabricadas en las boticas, hacia otras formas farmacéuticas fabricadas a nivel industrial como las ampolletas. Esta reorientación en los temas de investigación, se alineó con los nuevos campos laborales a los que tuvieron acceso los farmacéuticos en la coyuntura social en la que perdieron la batalla por conservar la tenencia y la regencia de las farmacias. Los químicos farmacéuticos encontraron aceptación en la ejecución de nuevas tareas aplicadas al análisis químico, mismo que dominaban cómodamente.

En este contexto, la capacidad científica y técnica de los farmacéuticos permitió encontrar a la vuelta del siglo xıx una salida a la crisis de identidad que había puesto en riesgo la subsistencia de su rol social a partir de su incursión en otras actividades relacionadas con aspectos sanitarios como la detección y prevención de diferencias en la preparación de fórmulas, un problema heredado del periodo anterior que había sido alentado por una legislación confusa y hasta cierto punto contradictoria, y en la comprobación de la calidad de alimentos y bebidas. En los años posrevolucionarios esta labor se dirigiría por completo a la estandarización de fórmulas y métodos de control de calidad de los medicamentos y otros insumos.

Si bien los cambios en la orientación de la actividad farmacéutica tardarían tiempo en reflejarse en los programas de estudio, en las tesis estudiadas la selección de los nuevos temas relacionados con el análisis químico (principalmente de alimentos), bioquímico, bacteriológico y toxicológico deja claro el cambio en el perfil profesional y marca una diferencia importante con las tesis realizadas entre 1867 y 1897 estudiadas por Ortiz-Reynoso (2002). Por otro lado también es cierto que algunos temas trabajados por los alumnos tienen continuidad con los que fueron elegidos en los treinta años anteriores, y en todo caso el análisis químico permanece como el hilo conductual de la profesión farmacéutica.

Por otra parte, puede verse una continuidad en la formación de redes de trabajo entre los profesores de la carrera de Farmacia y sus alumnos; en la ENM, Morales, Noriega y Lucio fueron los profesores de Castañares, Caturegli, Bezanilla Testa, Lisci, Maria y Campos, Herrera Rey, Lozano y Castro, Luque y Sánchez Mejorada, con los cuales formaron una estrecha red de colaboración. A su vez, estos últimos trabajaron de forma cercana con la siguiente generación ya formada en la Facultad de Química, que eventualmente establecería la Sociedad Química de México en 1926. 
La incorporación de la carrera a la Facultad de Química y Farmacia, consolidó la metamorfosis del farmacéutico mexicano que pasó de ser un profesional fincado en su trabajo en la botica y en contacto estrecho con el paciente, a ser un avanzado en el análisis químico y las técnicas de laboratorio, desvinculado de la práctica médica.

Casi dos décadas después, en 1937 la Universidad Nacional Autónoma de México cambiaría la denominación una vez más a la de Químico-Farmacéutico-Biólogo, consolidando la incorporación de los análisis de alimentos y bioquímico-clínicos reflejados en los temas de las tesis estudiadas, al campo profesional de los farmacéuticos mexicanos. La nueva carrera comenzaría a ofrecerse en las universidades estatales (algunas con énfasis en áreas específicas como alimentos, farmacia y análisis clínicos) y se popularizaría gracias a sus elevados índices de empleabilidad.

\section{BiBLIOGRAFÍA}

Aceves, Patricia, "La crisis de la farmacia en México en el cambio de siglo (xixxx)”, en Francisco Javier Dosil y Gerardo Sánchez (eds.), Continuidades y rupturas. Una historia tensa de la ciencia en México, México, Universidad Nacional Autónoma de México, Instituto de Investigaciones Históricas, Facultad de Ciencias/Universidad Michoacana de San Nicolás de Hidalgo, 2010, p. 311-340. Azuela, Luz Fernanda, y Rafael Guevara-Fefer, "La ciencia en México en el siglo XIX: una aproximación historiográfica”, Asclepio, v. L, n. 2, 1998, p. 77-105.

Christoph, Friedrich, "The Beginnings of the Industrial Era of Pharmacy", en Regine Pötzsch (ed.), The Pharmacy Windows on History, Basilea, Roche, 1996, p. 243-255.

Garritz, Andoni, y José Luis Mateos, Historia de la Facultad de Química de la Universidad Nacional Autónoma de México. Su primer siglo: 1916-2016, México, Universidad Nacional Autónoma de México, 2015.

Godínez, Rogelio, "Los primeros medicamentos químicos en México (1917-1940)", Boletín de la Sociedad Química de México, v. 6, n. 1, 2012, p. 8-14.

Godínez, Rogelio, y Patricia Aceves, Proyectos, realidades y utopías. La transformación de la Farmacia en México, 1919-1940, México, Universidad Autónoma Metropolitana Unidad Xochimilco, División de Ciencias Biológicas y de la Salud, 2014.

Godínez, Rogelio, Liliana Schifter y Mariana Ortiz-Reynoso, "Llegada de las ampolletas inyectables a México y Estados Unidos. Diferencias y similitudes en la práctica farmacéutica (1896-1939)", Estudios de Historia Moderna y Contemporánea de México, n. 57, 2019, p. 239-287. 
Hinke, Nina, El Instituto Médico Nacional. La política de las plantas y los laboratorios a finales del siglo XIX, México, Instituto Politécnico Nacional, Centro de Investigación y de Estudios Avanzados/Universidad Nacional Autónoma de México, 2012.

LEÓN-Olivares, Felipe, “Esther Luque: primera farmacéutica mexicana”, Educación Química, v. 21, n. 2, 2010, p. 150-154.

Marcial-Avendaño, Armando, “Antecedentes del Instituto Médico Nacional y los primeros años de trabajo de la Sección 3a. de Fisiología”, Boletín Mexicano de Historia y Filosofía de la Medicina, v. 10, n. 1, 2007, p. 21-27.

Martínez, Sandra, Desarrollo y transformación de la farmacia en México (18901920), el caso de las primeras mujeres farmacéuticas, tesis de licenciatura en Historia, México, Universidad Nacional Autónoma de México, Facultad de Filosofía y Letras, 2003.

, La Facultad de Ciencias Químicas y el proyecto de industrialización en México (1916-1937), tesis de maestría en Historia, México, Universidad Nacional Autónoma de México, Instituto de Investigaciones Históricas, 2016.

Martínez, Sandra, Patricia Aceves y Alba Morales-Cosme, "Una nueva identidad para los farmacéuticos: la Sociedad Farmacéutica Mexicana en el cambio de siglo (1890-1919)”, Dynamis, v. 27, 2007, p. 263-285.

"La transformación de una profesión. Las primeras farmacéuticas mexicanas”, en México siglo XX, México, Archivo General de la Nación, 1999, t. 1, p. 613-637.

Mendieta y NúÑEz, Lucio, “La administración pública”, en México: 50 años de Revolución. III. Política, México, Fondo de Cultura Económica, 1961, p. 85-99.

Morales-Sarabia, Angélica, y Patricia Aceves, "Datos para la Materia Médica Mexicana (1894-1908): plantas medicinales, terapéutica y nacionalismo”, Circumscribere, n. 9, 2010, p. 11-28.

Morales-Sarabia, Angélica, y Mariana Ortiz-Reynoso, "Research on Psychoactive Plants at Mexico’s National Medical Institute, 1888-1915”, Circumscribere, n. 16, 2015, p. 123-137.

Ortiz-Reynoso, Mariana, "Farmacia química en el siglo Xix mexicano. Una mirada a través de los alcaloides", en Signa naturalia. Concepciones y prácticas en torno a la materia médica, la farmacia y la salud (siglos XVI-XX), México, Universidad Nacional Autónoma de México, Centro de Investigaciones Interdisciplinarias de Ciencias y Humanidades, 2016, p. 163-197.

Ortiz-Reynoso, Mariana, y Patricia Aceves, "La legislación farmacéutica en México: disposiciones sobre el ejercicio profesional, 1917-1973”, Revista Mexicana de Ciencias Farmacéuticas, v. 45, n. 1, 2014, p. 26-34. 
Ortiz-Reynoso, Mariana, Las tesis de farmacia del siglo XIX mexicano, México, Universidad Autónoma Metropolitana-Unidad Xochimilco/Sociedad Química de México/Colegio Nacional de Químicos Farmacéuticos Biólogos, 2002.

Ortiz-Reynoso, Mariana, Javier Puerto y Patricia Aceves, "La reglamentación del ejercicio farmacéutico en México. Parte I (1841-1902)”, Revista Mexicana de Ciencias Farmacéuticas, v. 39, n. 1, 2008, p. 12-19.

Ortiz-Reynoso, Mariana, Martha Díaz-Flores, Hariz Islas-Flores, Liliana Schifter-Aceves, “Técnicas e instrumentos químico-farmacéuticos en México (18491925)”, Ciencia Ergo-Sum, v. 24, n. 1, 2017, p. 54-64.

Ortiz-Reynoso, Mariana, Liliana Schifter-Aceves, Valeria Zepeda-Trejo, "Pharmaceutical Patents in Mexico at the Beginning of the 20th Century", en Historia da Ciencia na PUC-SP: uma viagem de 20 anos, San Pablo, Editora da Pontificia Universidade Católica de São Paulo (2019, en prensa).

Portes Gil, Emilio, "Sentido y destino de la Revolución Mexicana”, en México 50 años de Revolución. III. Política, México, Fondo de Cultura Económica, 1961, p. 479-585.

Puerto, Javier, “The Apothecary in the 19th Century”, en Regine Pötzsch (ed.), The Pharmacy Windows on History, Basel, Roche, 1996, p. 240-250.

RODRÍGUEZ-BENítez, Leonel, Las tesis académicas de las ciencias químico biológicas en Sinaloa, 1875-1974. Catálogo documental histórico de la química y la farmacia en el noreste de México, México, Universidad Autónoma de Sinaloa, 2017.

Rodríguez-Nozal, Raúl, y Antonio González-Bueno, Entre el arte y la técnica. Los orígenes de la fabricación industrial del medicamento, Madrid, Consejo Superior de Investigaciones Científicas, 2005.

Rondero, Javier, “Características del nacionalismo”, en México. 50 años de Revolución. III. Política, México, Fondo de Cultura Económica, 1961, p. 293-316.

SCHIFTER, Liliana, Espíritu e identidad farmacéuticos. La construcción de la farmacopea mexicana (1846-2011), México, Universidad Nacional Autónoma Metropolitana, Unidad Xochimilco, 2014.

"Las farmacopeas mexicanas en la construcción de la identidad nacional", Revista Mexicana de Ciencias Farmacéuticas, v. 45, n. 2, 2014, p. 43-54.

Schifter, Liliana, y Angélica Morales-Sarabia, "La trayectoria de Francisco Río de la Loza en la Sección de Química Analítica del Instituto Médico Nacional”, Revista Mexicana de Ciencias Farmacéuticas, v. 43, n. 4, 2012, p. 69-78.

Schifter, Liliana, y Patricia Aceves, "The Development of Chemistry at the National Medical Institute, 1888-1915”, Circumscribere, 2015, v. 16, p. 41-56.

Schifter, Liliana, y Patricia Aceves, "Los farmacéuticos y la química en México (1903-1919): prácticas, actores y sitios”, Estudios de Historia Moderna y Contemporánea de México, n. 51, 2016, p. 72-92. 
Schifter, Liliana, Angélica Morales-Sarabia y Patricia Aceves, "La Farmacología Nacional y la Farmacopea Mexicana”, Estudios do Século, v. 21, n. 12, 2012, p. 197-216.

Simon, Josep, Communicating Physics: The Production, Circulation and Appropiation of Ganot's Textbooks in France and England, 1851-1887, Londres, Pickering and Chatto, 2011.

Speckman Guerra, Elisa, "El Porfiriato", en Nueva historia mínima de México, México, El Colegio de México, 2004, p. 192-224.

Stichweh, Rudolf, "Differentiation of Scientific Disciplines: Causes and Consequences”, en Encyclopedia of Life Support Systems, Paris, unesco, 2003.

Teja Zabre, Alfonso, Guía de la historia de México, México, Secretaría de Educación Pública, 1944. 